BULLETIN Bulletin hispanique

HispaniquE Université Michel de Montaigne Bordeaux

114-1 | 2012

Varia

\title{
La inesperada trayectoria política e institucional de un dramaturgo neoclásico
}

Sobre Cristóbal María Cortés y Vitas

Fernando Mikelarena Peña

\section{OpenEdition}

\section{Journals}

Edición electrónica

URL: http://journals.openedition.org/bulletinhispanique/1823

DOI: 10.4000/bulletinhispanique.1823

ISSN: $1775-3821$

Editor

Presses universitaires de Bordeaux

Edición impresa

Fecha de publicación: 1 junio 2012

Paginación: 153-193

ISBN: 978-2-86781-812-7

ISSN: 0007-4640

Referencia electrónica

Fernando Mikelarena Peña, « La inesperada trayectoria política e institucional de un dramaturgo neoclásico », Bulletin hispanique [En línea], 114-1 | 2012, Publicado el 01 junio 2015, consultado el 03 mayo 2019. URL : http://journals.openedition.org/bulletinhispanique/1823 ; DOI : 10.4000/ bulletinhispanique.1823 


\title{
La inesperada trayectoria política e institucional de un dramaturgo neoclásico. Sobre Cristóbal María Cortés y Vitas
}

\author{
Fernando Mikelarena Peña \\ Universidad de Zaragoza
}

Cet article traite de la surprenante trajectoire politique et institutionnelle d'un dramaturge néo-classique, le navarrais Cristóbal María Cortés et Vitas. Membre du Parlement de Navarre de 1794 à 1797, il a joué un rôle très important pendant la Guerre de la Convention. Membre de la Diputación entre 1797 et 1801, il a été le représentant de la Navarre à Madrid lors de l'offensive de Godoy pendant ces années-là. Divers documents, présentés ici, attestent qu'il a défendu la Navarre face à l'incertitude de juillet 1795 ainsi que le régime foral navarrais en 1800-1801.

En este artículo se examina la inesperada trayectoria politica e institucional de un dramaturgo neoclásico, el navarro Cristóbal María Cortés y Vitas. Miembro de las Cortes de Navarra de 1794-1797 su papel fue importante durante la Guerra de la Convención. Miembro de la Diputación entre 1797 y 1801, fue el representante de Navarra en Madrid ante la ofensiva de Godoy de esos años. Se presentan varios documentos suyos que prueban su defensa de Navarra ante la incertidumbre de julio de 1795 y su defensa del régimen foral de Navarra en 1800-1801.

This article examines the unexpected political and institutional trajectory of a neoclassical playwright, the Navarrian Cristóbal Maria Cortés y Vitas. A member of the Parliament of Navarre from 1794 to 1797, he played an important role during the Convention's War: a member of the Diputacion of Navarre from 1797 to 1801, he was the representative of Navarre in Madrid during the offensive of Godoy in those years. We will present several documents that testify he defended Navarre when facing the uncertainty of July 1795, as well as his defence of the "Fueros" from Navarre, in 1800-1801.

Mots-clés : Navarre, Cortes de la Navarre, Diputación de la Navarre, Guerre de la Convention, dramaturges néoclassiques. 


\section{Datos biográficos de Cristóbal Cortés y Vitas}

Cristóbal María Cortés y Vitas nació en Tudela (Navarra) en el año 1740 y falleció en la misma ciudad en 1804. Fue socio fundador de la Real Sociedad Tudelana de los Deseosos del Bien Público, desde su fundación de facto en 1773, mucho antes de su aprobación cinco años después, desempeñando los cargos de secretario interino, director en funciones, vicedirector, secretario y censor. En una etapa de su vida residió en Madrid. Tras regresar a su ciudad natal a finales de los años setenta participó en la administración municipal de la misma, siendo, según hemos visto en nuestro repaso de los libros de actas municipales y de la Sociedad Tudelana de los Deseosos del Bien Público, regidor en 1778 y 1788 y alcalde en 1790 . También, como veremos, fue representante por Tudela en las Cortes de Navarra de 1794-1797 y de 1801, siendo miembro de la Diputación entre ambas reuniones ${ }^{1}$.

Fue el primer dramaturgo navarro, figurando en una segunda línea de la tragedia neoclásica española. Su obra literaria principal se compone de varias piezas dramáticas, algunas de ellas impresas y otras conservadas en estado de manuscrito. Entre las que se publicaron están Atahualpa (Madrid, 1784 y Barcelona, 1799) y Eponina o el amor conyugal (Madrid, 1801), premiada por la RAE en el año 1800. Entre las que se conservan en manuscrito está Sancha de Navarra o el amor conyugal. Por otra parte, Mariano Sanz mencionó como suyas otras cuatro obras, la tragedia Pelayo de 1774; las comedias El tono del gran mundo, de 1774, y Balbina, de 1788; y el texto en prosa y en verso Anatomía del amor, de 1762. Otros autores añaden a su producción otros tres dramas titulados respectivamente Ana Bolena, El conde don García de Castilla y La venganza, estos dos últimos en manuscrito y datados en los años ochenta del setecientos ${ }^{2}$. Como se ve, «la mayoría son tragedias de tema nacional», respondiendo al intento de los escritores españoles de "crear una tragedia autóctona». Llama la atención que algunas de las obras de Cortés se titulen exactamente igual, o de forma parecida o directamente relacionada, que otras tragedias de otros autores ${ }^{4}$.

1. Mariano Sáinz Pérez de Laborda, Apuntes tudelanos, Tudela, Gráficas Mar, 1969, pp. 373375; José Ramón Castro Álava, Autores e impresos tudelanos, Pamplona, Institución Príncipe de Viana, 1963, pp. 142-177; Fernando González Ollé, Introducción a la historia literaria de Navarra, Pamplona, Institución Príncipe de Viana, 1989, pp. 139-153; Ángel-Raimundo Fernández, "Dos dramaturgos navarros en la transición del siglo XVIII al XIX", Príncipe de Viana, 2003, 230, p. 715; María del Rosario Pérez Arche, «La biblioteca de un escritor del siglo XVIII: Cristóbal María Cortés y Vitas», Príncipe de Viana, 1993, 198, p. 186, nota 4.

2. Ángel-Raimundo Fernández, op. cit., pp. 717-718.

3. María del Rosario Pérez Arche, op. cit., p. 186, nota 2.

4. El Pelayo de Cortés recuerda a las obras homónimas de Jovellanos, publicada en 1769 y 1792 y conocida también por Munuza, y de Quintana, publicada en 1805, vinculándose asimismo con la Hormesinda de Nicolás Fernández de Moratín, por cuanto en ellas se narran los amores de Hormesinda, hermana de Don Pelayo, con Munuza, gobernador árabe de Gijón. También el Atahualpa recuerda al Motezuma de Bernardo María de la Calzada (Madrid, 1784). En cambio, la Sancha de Navarra de Cortés no coincide temáticamente con Don Sancho García (Madrid, 1771) de Cadalso, y con La condesa de Castilla de Álvarez Cienfuegos (1798) por 
Por otra parte, de todas esas obras, el Atahualpa ha sido la más estudiada5.

También publicó diversas obras no dramáticas. Así por ejemplo, la Égloga entre Fileno y Menandro, leída en la Sociedad Tudelana en 1779 y publicada en las Memorias de la misma editadas en Madrid en $1787^{6}$, y en la que festeja su retorno definitivo a la capital ribera; El triunfo de la Paz, un largo poema impreso en Madrid en 1785 en el que se sintetiza la historia de Tudela con ocasión de la erección a catedral de su iglesia principal; y el poema latino en hexámetros Chrisbalto Ecloga qua Pastorem suum optimum, editado en Pamplona en 1786. Asimismo, hacia 1801 intentó publicar otra obra, titulada Ensayo en cien problemas, de la que se conservan dos versiones manuscritas, en la Biblioteca Nacional y en el Archivo Histórico Nacional respectivamente, aunque sin éxito, debido a la evaluación negativa del censor que no comprendió la mezcla de poesía y de álgebra en la que se basaba ${ }^{7}$. Del repaso de las actas de la Real Sociedad Tudelana de los Deseosos del Bien Público se desprende que Cortés leyó en dicha entidad varias obras, todas ellas desaparecidas: un Prólogo para un Compendio de la Historia de Navarra, o Plan para la formación de dicho Compendio para la instrucción de los Jóvenes de el Reino en $1780^{8}$; un Plan intitulado Proiecto de un Seminario Patriótico para la educación de la Noble Juventud de este Pais en 17829; y un Discurso sobre el mejor uso de los abonos en el cultivo de las tierras, determinándolo a las tierras, y campos de esta Ciudad en $1785^{10}$.

Nos ha interesado la figura de Cristóbal Cortés porque hemos detectado en la misma un perfil ciertamente poco esperable en un dramaturgo neoclásico, el de una persona comprometida desde el punto de vista político y desde el punto de vista institucional en la defensa del cuerpo político diferenciado, inscrito en la monarquía hispánica, al que pertenecía (es decir, el Reino de Navarra, que, como es sabido, tras su conquista por las tropas castellanas en 1512, conservó hasta 1841, dentro de la Corona española una amplia autonomía

cuanto aquella obra narra el amor de la protagonista por su marido el conde de Castilla que motivará su sacrificio al entregarse al rey de León para salvar a aquél, mientras que las otras dos obras se centran en los amores de la madre de Sancho García con Almanzor. Cf. Francisco Lafarga, "Territorios de lo exótico en las letras espańolas del siglo XVIII», Anales de literatura española, 1994, 10, p. 187.

5. Fernando González Ollé, «Atahualpa, tragedia de Cristóbal María Cortés», en Homenaje a Antonio Gallego Morell, Granada, Universidad de Granada, 1989, v. I, pp. 83-90; Ignacio Arellano, El Atahualpa de Cristóbal Cortés. Una tragedia neoclásica, Pamplona, Eunsa, 1993; María del Rosario Pérez Arche, «Atahualpa, una tragedia neoclásica al servicio de unas ideas», Príncipe de Viana, 1994, 201, pp. 191-203; Francisco Tovar, «La tragedia neoclásica de tema americano: Atahualpa de Cristóbal Cortés», en El teatro español del siglo XVIII, Lleida, Universidad de Lleida, 1996, Tomo II, pp. 751-782.

6. Memorias de la Real Sociedad Tudelana de los Deseosos del Bien Público, Madrid, 1787, pp. 180-203.

7. Ángel-Raimundo Fernández, op. cit., p. 716.

8. Archivo Municipal de Tudela, Actas de la Real Sociedad Tudelana de los Deseosos del Bien Público, Libro 1, ff. 68V, 71v, 78 y 81v.

9. Ibid., ff. 109 y $141 \mathrm{v}$.

10. Ibid., f. 187. 
legislativa, judicial y administrativa, poseyendo sus Cortes propias, su Gobierno administrativo a través de la Diputación, sus tribunales y sus fronteras propias, en los Pirineos con Francia y en el Ebro con Castilla). Y ello, tanto en el contexto de las incertidumbres propias de la Guerra de la Convención respecto al status políticoinstitucional de Navarra (y de las Provincias Vascongadas habría que añadir), como en el de la ofensiva que tras dicho conflicto planteó el gobierno central de Godoy contra el régimen foral de aquellos cuatro territorios. Como se verá, Cristóbal Cortés desempeñó un papel muy activo en las Cortes navarras de 1794-1797, así como en la Diputación subsiguiente, y fue el autor de textos muy elocuentes en relación con la crítica coyuntura de finales de julio de 1795, en la que los convencionales franceses estuvieron a punto de entrar en Pamplona y conquistar Navarra, y en relación con las presiones políticas a las que fue sometido el autogobierno navarro a la altura de 18001801. Toda esa faceta político-institucional de Cristóbal Cortés ha sido hasta ahora absolutamente desconocida, no habiendo recibido la suficiente atención por parte de casi ningún autor, a excepción de las esporádicas noticias que da Rodriguez Garraza ${ }^{11}$ sobre el documento de julio de 1795, obra de aquél y al que ya hemos hecho mención, y sobre las gestiones que realizó en 1800-1801 en Madrid.

No obstante, a pesar de ese perfil de persona comprometida con la patria más inmediata, curiosamente en sus obras dramáticas no se constata ninguna ambientación en la historia de Navarra, ni ninguna evocación elogiosa a los aspectos a los que sí se referirá desde aquella otra faceta personal.

Con todo, antes de centrarnos en aquel perfil político-institucional, profundizaremos también en la faceta historiográfica de Cristóbal Cortés, aspecto éste también desconocido, en la medida en que nos proporciona algunas claves del pensamiento de Cortés acerca de la historia de Navarra, concomitante, como se verá, con el discurso más tendente a resaltar el particularismo navarro.

\section{La Vertiente historiográfica de Cortés}

Cuando hablamos de la vertiente historiográfica de Cristóbal Cortés no nos referimos a su labor como historiador, inexistente en cuanto que no elaboró ningún texto de análisis histórico, aparte de ese mencionado Prólogo para un Compendio de la Historia de Navarra, o Plan para la formación de dicho Compendio para la instrucción de los Jóvenes de el Reino de 1780, sino a la constatación de que disponía de amplios conocimientos historiográficos en cuanto que sus dramas se fundamentaban en personajes y sucesos del pasado y en cuanto que la Diputación le consideró un experto de cara a la evaluación de una historia de Navarra que le fue presentada en 1790.

11. Rodrigo Rodriguez Garraza, Tensiones de Navarra con la Administración central, Pamplona, Institución Príncipe de Viana/CSIC, 1974. 
En efecto, el 11 de agosto de 1790 la Diputación le encargó a Cortés «examinar a fondo y con la atención y cuidado» que se prometía «de su genio laborioso, conocido talento, y abentajada instrucción» un manuscrito titulado Epitome de la Historia de Navarra y escrito por un tal Manuel de Ynca y Yupanqui, que, a la sazón, se encontraba preso en la Ciudadela de Pamplona ${ }^{12}$. La solicitud era razonada por la Diputación por ser «asumpto de consideración» y por considerar que no era «decoroso proteger este pensamiento no siendo obra acabada y conforme a las delicadas leyes de los Compendios y menos existiendo el de el Padre Miguel de Elizondo ${ }^{13}$ que aunque no se alle del todo perfecto puede serbir y efectibamente presta su uso en defecto de otro que sea caval». La Diputación le solicitaba «el concepto que forma», si advertía «algunos defectos o lunares en la substancia, y parte exempcial de la Historia, en el estilo o en las demás partes que contribuyen a la perfección de semejantes obras y en fin en que circunstancias pudiera mejorarse» ${ }^{14}$.

No vamos a detenernos en los pormenores de la negativa evaluación del manuscrito por parte de Cortés reflejados en carta enviada el 23 de septiembre, sino tan sólo en las consideraciones presentes en la misma que reflejarían su pensamiento historiográfico de fondo. Con todo, antes de nada, es preciso advertir que Cortés pudo acceder a un amplio caudal de conocimientos históricos, más que a través de su biblioteca particular, que contaba con un número limitado de obras de entidad de naturaleza historiográfica (una veintena, de los que los más notorios eran los Anales de Aragón de los principales cronistas aragoneses, las Guerras civiles de Francia de Dávila, la Conquista de México de Solís, la Historia universal de Buffier y el Siglo de Luis XIV de Voltaire; no constando ningún titulo relativo a la historia de Navarra) ${ }^{15}$, por medio de la biblioteca mancomunada de los socios de la Real Sociedad Tudelana de los Deseosos del Bien Público.

Esa entidad prestó gran interés a la Historia, denominándose una de sus cuatro comisiones precisamente Comisión de Historia, Política y Buenas Letras. Aún cuando esa Comisión tenía como fin esencial el de ahondar en las características

12. Manuel Inca Yupanqui, mestizo descendiente de los emperadores incas, entró como guardia marina en la Real Armada Espańola en 1791 (Jaime Vicens Vives, Historia Social y económica de España y América, Barcelona, 1975, v. 4, p. 338). Llegó a ocupar en España un puesto de comisario de guerra e intendente interino del ejército del Alto Aragón durante la guerra de la Independencia. Fue juzgado en consejo de guerra por entregar la plaza de Jaca a los franceses (Marie Laure Rieu de Millán, «À propos de la «trahison» de l'inca Yupanqui, commisaire de guerre de la place de Jaca (mars-avril 1809), d'après des documents inédits», Cahiers du Monde Hispanique et Luso-Brésilien, 1979, 33, pp. 49-75).

13. Se refiere a la síntesis de los volúmenes de los Anales del Reino de Navarra de José de Moret y de Francisco de Alesón publicada en 1732 por el tercer cronista oficial, Pablo Miguel de Elizondo, bajo el título Compendio de los cinco tomos de Annales de Navarra, publicada.

14. Archivo General de Navarra (AGN), Reino, Sección de Historia, Literatura ..., Legajo 3, Carpeta 11: Censura dada con encargo de la Diputación del Reino por Don Cristóbal María Cortés vecino de Tudela al Epitome de la Historia de Navarra escrito por Don Manuel de Ynca Yupanqui preso en la Ciudadela de Pamplona. Resulta de las contestaciones que no se adoptó la obra y que la diputación deseaba se encargase de escribirla el mismo Cortés (1790).

15. María del Rosario Pérez Arche, op. cit., pp. 189-190. 
de la historia económica de Tudela y de la Ribera, también reconocía que, como paso previo, eso requería «una grande aplicación a instruirse en nuestras propias historias provinciales, fueros, leyes, estilos, costumbres de los Pueblos en la universalidad de sus rentas, arbitrios, ordenanzas, y autos acordados del Consejo; porque de la inspección atenta de todos estos documentos resulta un conocimiento práctico de los bienes y males del País, para que se pueda pensar con serios fundamentos en los medios de promover y aumentar los unos, cortar y extinguir los otros». Asimismo, también se apuntaba que "como las Historias nacionales y extrangeras dan también una multitud de luces con la noticia de sus exemplos y sucesos, para que adaptándolas a nuestro País en quanto sea conveniente le utilicemos con ellas, será su estudio muy recomendable para los encargos de esta comisión» ${ }^{16}$.

En un acuerdo de diciembre de 1778 los socios de la entidad determinaron la formación de una biblioteca mancomunada en la que cada uno aportaría sus libros. Para noviembre del año siguiente se elaboró una lista general de los libros de la biblioteca por parte precisamente del Marqués de San Adrián y del propio Cortés, lista que se ha conservado y en la que se relacionan los libros de cada tema aportados por cada socio, mencionando por bloques los de cada uno. De los 5.250 tomos totales, en el apartado de Historia se computaban $1.567^{17}$. En un artículo hemos analizado los libros de historia de esa biblioteca mancomunada, subrayando la importancia de muchas de las obras de la colección, así como su variedad en cuanto que pueden localizarse ejemplares notables sobre historia universal y sobre cada uno de los continentes, sobre historia de los diversos países europeos, sobre historia de España, sobre historia de Navarra y Aragón, sobre historia de las diversas regiones españolas, sobre historia antigua, sobre historia biográfica, y sobre metodología histórica y ciencias auxiliares de la historia ${ }^{18}$. Sobre historia de España, por ejemplo, encontramos en esta colección las obras primordiales de los grandes historiadores españoles de los siglos XVI, XVII y XVIII tales como Florián de Ocampo, Ambrosio de Morales, Esteban de Garibay, Juan de Mariana, Prudencio de Sandoval, Diego Saavedra Fajardo, Rodrigo Mendez Silva, Francisco de Cepeda, José Pellicer de Ossau y Tóvar, Enrique Flórez, José Álvarez de la Fuente y Jean Baptiste Duchesne. La biblioteca de la Tudelana también disponía no sólo de las obras de los cronistas navarros de la segunda mitad del siglo XVII y de la primera mitad del siglo XVIII (Moret, Alesón y Elizondo), surgidas de la refutación de los cronistas aragoneses, sino también de la primera historia de Navarra escrita por un navarro que se imprime: la Historia apologética y descripción del Reino de

16. Memorias de la Real Sociedad Tudelana de los Deseosos del Bien Público. Madrid: 1787, pp. 172-173. Citado en Fernando Mikelarena Peńa, «El final de una biblioteca centenaria. La historia de la Biblioteca de la Real Sociedad Tudelana de los Deseosos del Bien Público", Revista Internacional de los Estudios Vascos, 2008, 53-1, pp. 194-195.

17. Fernando Mikelarena Peña, op. cit., pp. 199-200.

18. Fernando Mikelarena Peña, «Los libros de Historia de la Biblioteca de la Sociedad Tudelana de los Deseosos del Bien Público», Cuadernos de Investigación Histórica, 2008, 25, pp. 363-414. 
Navarra de Juan de Sada y Amézqueta. Por último, no faltaban las obras más relevantes sobre historia de Aragón publicadas en las décadas finales del siglo XVI y a lo largo del siglo XVII, como las de Zurita, Blancas, Argensola, Andrés de Uztárroz, Dormer, Pedro Abarca, etc ${ }^{19}$.

Pues bien, teniendo en cuenta, por todo lo anterior, que Cortés podía ser poseedor de un amplísimo bagaje de conocimiento histórico en relación con la historia de España, de Aragón y de Navarra, en los comentarios que expresan su parecer historiográfico se nos revela como un tenaz seguidor de las tesis de Joseph de Moret, el mejor historiador navarro de la Edad moderna y con quien el discurso historiográfico de defensa del particularismo navarro llega a su máxima expresión, saliendo, además, aquél al encuentro de las críticas lanzadas al mismo por Manuel Risco en su obra La Vasconia. Tratado preliminar a las santas iglesias de Calahorra, y de Pamplona: en que se establecen todas las antigüedades civiles concernientes a la región de los Vascones desde los tiempos primitivos hasta los Reyes primeros de Navarra, obra publicada en Madrid en 1779 como tomo 32 de la España Sagrada, colección de historia eclesiástica española. De hecho, en relación con ello, sin mencionar al autor riojano en ningún momento, Cortés afirma que «todo lo que sufre nuestra Historia proviene de aquella poca luz, que ofrecen los primeros tiempos, y del empeño de los Aragoneses en atribuirse exclusivamente muchos de los primeros pasos que tal vez dieron bajo la dependencia de los Reyes de Pamplona. Este delicado punto le esfuerza Moret con toda la escrupulosidad de sus sabias investigaciones».

Por otra parte, resulta muy expresivo que Cortés considere que entre «lo substancial de la Historia» debe estar incluído «lo que pertenece a límites del Reyno en todos tiempos, a la sucesión de los Reyes, espresión de sus Hijos, y mugeres, hechos particulares como hazañas, o debilidades, ganancias, o pérdidas, y en una palabra todo lo que está íntimamente unido a su constitución, qual es la Religión, y el gobierno».

No deja tampoco de ser indicativo el énfasis que pone Cortés en la independencia de los vascones tanto respecto de Roma como de los visigodos. En relación con Roma, Cortés aparece como un seguidor radical del apologético discurso cantabrista de Moret en dos párrafos. En su opinión «la región de los Vascones llamados después navarros vivió siempre con particular independencia [...]. Hasta Augusto no se especifica guerra formal, y directa contra ellos; todas son pasageras, y por ocasión, que no alteran la forma de su govierno» [...]. Aún después de la guerra de Augusto dirigida más precisamente contra los Cántabros, como lo demuestra el sitio en que estuvo la fuerza de ella; no suena movimiento, o mudanza de gobierno en los Vascones, bien que se dice allanada toda España. Éstos conservan su lengua, por más que los Romanos avían introducido la suya en todo lo que conquistaron en España, prueva nada equívoca de aver sido pasagera la dominación, o sólo honoraria como el que se pone bajo la protección de otro soberano sin pérdida de su libertad, y gobierno».

19. Fernando Mikelarena Peña, «Los libros de Historia... », pp. 363-414. 
En relación con la monarquía visigótica, Cortés reitera a una con Moret que «En los trescientos ańos desde la entrada primera de los Godos en Espańa hasta la de los Árabes (Moret folio 113) jamás suena en alguna de sus memorias Conde alguno, que a la usanza de ellos tuviese cargo o gobierno sobre los Vascones. Los Vascones navarros (folio 127) aunque estrechados en los últimos reinados vivían al tiempo (de la pérdida de España) en quanto se puede entender, libres de la sujeción a ellos».

También es rotundo en su seguimiento a Moret al hablar de los límites geográficos de la monarquía navarra. Además de incluir las comarcas propiamente navarras, Cortés recuerda las aserciones de Moret acerca de la pertenencia a los vascones de las tierras de la Jacetania y del condado primigenio de Aragón, aval de la preeminencia de los reyes de Navarra sobre los aragoneses, rematando que «esta dependencia, y sujeción de Aragón a Navarra, es cosa esencial, que no debe omitirse».

Rememorando tal vez la deconstrucción por parte de Risco del discurso historiográfico en que los cronistas navarros habían fundamentado la diferencialidad de Navarra, al ver los argumentos de fondo empleados por Cortés en su crítica a Inca Yupanqui y el tono de su convencida adhesión a Moret, a los miembros de la Diputación pudo ocurrírseles que en el dramaturgo tudelano habían encontrado al hombre ideal para la realización de una síntesis de la historia de Navarra. Al menos, eso es lo que se desprende de la carta de agradecimiento escrita por Diego María Basset, secretario de la Diputación, a Cortés el 16 de octubre de 1790 a raíz de haber cumplimentado el encargo evaluador. En la carta Basset comentaba que «aviendo antes entendido que vmd. rebolbía entre sí mismo la idea de disponer un compendio de los referidos Anales siguiendo el método que el Padre Duquesne en el de la Historia general de España traducido por el Padre Ysla cifrando a la frente en berso un sumario de todos los Anales, se han insinuado deseosísimos [los miembros de la Diputación] de que vmd. emprenda esta obra, y con la más viva eficaz ansia de que lo egecutase con toda la posible brevedad porque sería de su mayor satisfacción dando por supuesto el caval desempeño y el acierto; y no se han determinado desde luego a insinuarselo a vmd. por el reparo de si lo llevaría a bien aunque se prometen e inclinan a que se servirá complacerles; y así Amigo vmd. interesa en ello, igualmente el Reyno, y mirando por sí, y por la Patria, y que no nos benga un estraño a desfigurar nuestra historia debe vmd. sacrificar su abilidad, su aplicación, y estudio a este desempeño, que me parece le hará tanto honor como cualquiera otra tarea a que se dedicase» ${ }^{20}$.

Sin embargo, la oferta cayó en saco roto. En su respuesta Cortés la valoró, pero los argumentos negativos (entre ellos, sobre todo, el que no se considerara

20. AGN, Reino, Sección de historia, Literatura ..., Legajo 3, Carpeta 11: Censura dada con encargo de la Diputación del Reino por Don Cristóbal María Cortés vecino de Tudela al Epitome de la Historia de Navarra escrito por Don Manuel de Ynca Yupanqui preso en la Ciudadela de Pamplona. Resulta de las contestaciones que no se adoptó la obra y que la diputación deseaba se encargase de escribirla el mismo Cortés (1790). 
como un historiador propiamente dicho, así como las tareas que le exigía su cargo de alcalde de Tudela) pesaron más que ningunos otros ${ }^{21}$.

\section{Cristóbal Cortés y la Guerra de la Convención}

\section{III.1 La Guerra de la Convención en el frente vasconavarro}

Como es sabido, la Guerra de la Convención, fue un conflicto que enfrentó a la monarquía española y a la República francesa entre 1793 y 1795 durante la fase de mayor fervor revolucionario de la etapa inaugurada en Francia tras 1789, la de la Convención Nacional, dentro del conflicto general que enfrentó a Francia con la Primera Coalición. En esta coalición se conjuntaron diversos países europeos (como Austria, Prusia, Reino Unido, Países Bajos y España) para contener la Revolución Francesa. Esos países invadieron Francia por diversos lugares, consiguiendo algunas victorias al principio, siendo favorecidos, asimismo, por la apertura de un frente interior en la Vendée donde fuerzas contrarrevolucionarias apoyadas por la población lucharon contra el orden republicano. El levantamiento de levas en masa, reclutando a cualquier soldado en potencia entre los 18 y los 25 ańos en agosto de 1793, permitió a los franceses repeler a los invasores y a establecerse fuera de sus fronteras.

La guerra entre España y Francia transcurrió por los dos extremos pirenaicos, el occidental y el oriental. La campańa de 1793 en el frente vasconavarro se caracterizó por las estrategias defensivas de ambos contendientes. Únicamente el ejército espańol se aventuró a algunas acciones poco ambiciosas al otro lado de la frontera. A finales de julio de 1794 llegó la ofensiva convencional y la desbandada de las tropas españolas. Entre el 23 y el 29 de julio los franceses tomaron el valle de Baztán y las Cinco Villas, tomando posteriormente, en los primeros días de agosto, Oyarzun, Irún, Fuenterrabía y San Sebastián. El 9 de agosto los franceses ya estaban en Tolosa. El ejército español, mandado por el conde de Colomera, estableció una nueva línea de defensa en el río Deva, para evitar la invasión de Vizcaya. En Navarra, el fracaso de varias ofensivas francesas en octubre y noviembre, dirigidas a la toma de Pamplona, dieron lugar a la estabilización de la situación. El equilibrio se modificó en julio de 1795. Tras romper el general francés Moncey la línea defensiva del río Deva, Vitoria sería tomada el día 15 de ese mes y dos días después Bilbao. Finalmente la capital navarra, Pamplona, se salvó por los pelos, al firmarse el 22 de julio la Paz de Basilea. Por dicho acuerdo Francia renunció a las tierras que ocupaba en Navarra y Vascongadas a cambio de obtener la isla de Santo Domingo ${ }^{22}$.

21. Ibidem.

22. La descripción de la contienda en Joseba Goñi Galarraga, «La revolución francesa en el País Vasco: la guerra de la Convención", en Historia del Pueblo Vasco, San Sebastián, Erein, 1979, tomo 3, pp. 5-69. 
Más allá de los hechos militares, el episodio más conocido en el marco de esta contienda en la esfera de lo políticoinstitucional en el ámbito vasconavarro es la independencia de Guipúzcoa. El 5 de agosto de 1794 se rindió San Sebastián ante el general en jefe francés Moncey. La negociación de rendición fue llevada a cabo entre La Tour d'Auvergne, representante revolucionario, y el alcalde de la ciudad Michelena, pactando entre ellos el respeto a los Fueros, el culto y a las propiedades. Posteriormente, tras la ocupación de la provincia hasta el río Deba, entablaron negociaciones con los franceses el Diputado General de Guipúzcoa José Fernando Echave y su cuñado Joaquín María de Barroeta, los dos enciclopedistas y republicanos. Aunque los representantes de los convencionales, Pinet y Cavaignac, plantearon inicialmente la anexión a la República Francesa, lo que se debatió en las Juntas Generales guipuzcoanas reunidas en Getaria el 14 de agosto era que Guipúzcoa fuera provincia independiente, con status de neutralidad frente a Francia, así como el libre ejercicio de la religión católica y el respeto a los Fueros. No obstante, Pinet y Cavaignac rompieron las negociaciones el 19 de agosto, negándose a admitir cualquier otra posibilidad que no fuera la anexión y trasladando a la mayoría de las autoridades guipuzcoanas a Bayona. Con todo, frente a las tesis de Pinet y Cavaignac de incorporación sin más del territorio guipuzcoano a la República francesa, plasmada en un informe presentado al Comité de Salvación Pública y que fue apoyada por otros miembros de éste, hay que remarcar que existieron otros planteamientos. Un informe de Moncey de marzo de 1795, que también fue elevado a las autoridades termidorianas por Chaudron Rousseau y que sería asumido por Tallien, uno de los miembros de aquel Comité, hablaba de garantizar el dominio militar de los convencionales sobre Guipúzcoa permitiendo el libre ejercicio del culto católico y la restauración de las autoridades municipales y provinciales del territorio conquistado, proponiendo que éstas últimas resolvieran de nuevo a favor de su independencia respecto de España. Además, Moncey planteaba una medida complementaria de mayor radio geográfico: proponer a Vizcaya y a Álava la unificación con Guipúzcoa en una única entidad con los mismos contenidos políticos e institucionales que los que se plantearían a esta última. La creación de esa entidad política vasca, bajo la fórmula de República Independiente bajo la protección de Francia, tendría también como objetivo reducir la resistencia militar de los naturales. Las consideraciones de Moncey partían de su caracterización como democráticas de las instituciones forales de los tres territorios y de su opinión de la similitud existente entre éstas y las republicanas francesas. En apoyo de su idea de extender el proyecto, pensado inicialmente para Guipúzcoa, a Vizcaya y a Álava, Moncey menciona que ya antes de la entrada de los ejércitos revolucionarios franceses los diputados de los tres territorios «conspiraban en silencio para la reunión que deseamos ahora», así como que los tres ámbitos reunían las condiciones para formar una asociación política por sus «necesidades recíprocas, relaciones comerciales habituales, amistad y buena vecindad, identidad de principios políticos y el mismo odio para con el gobierno de Madrid». Finalmente, como último acto de lo que estamos diciendo el 10 de mayo de 1795 la diputación 
extraordinaria de la provincia de Guipúzcoa y las autoridades donostiarras se reunieron en asamblea para oír el discurso del representante del pueblo Chaudron Rousseau, que había elevado a París el informe de Moncey, en el que se les invitaba a aquéllos a reasumir sus poderes anteriores a la conquista francesa. Los representantes guipuzcoanos, en boca del diputado general Romero, expresaron su voluntad de asociarse a la República francesa. Al día siguiente, Chaudron Rousseau, en un informe remitido al Comité de Salvación Pública, se congratulaba del acuerdo alcanzado con Guipúzcoa y denotaba su confianza en los efectos positivos que dicho pacto tendría entre los vizcaínos. Por otra parte, entre las instrucciones que precisamente el 10 de mayo de 1795 el Comité de Salvación Pública trasladó al embajador de la República francesa en Basilea, encargado de negociar la paz con España, se mencionaba en el punto cuatro que Guipúzcoa quedaba en manos francesas ${ }^{23}$.

\section{III.2 La Guerra de la Convención y Navarra. Las reticencias iniciales de los representantes del rey}

La guerra de la Convención planteó tensiones desde el principio entre la monarquía y las instituciones navarras, máxime cuando en plena guerra se inauguraron unas Cortes de Navarra que durarían hasta 1797 y en las que se debatieron propuestas de alcance planteadas por los convencionales franceses, así como otras planteadas en el seno de la misma cámara acerca de la creación de un ejército navarro propio, todo ello en un ambiente de descontento de la población por la movilización militar y de surgimiento de algunas revueltas en las que se corearon lemas revolucionarios.

Ya a principios de 1793 comenzó una larga diatriba entre las instituciones navarras y el virrey en relación con la movilización de contingentes militares navarros. En marzo de ese año la Diputación contestó a la orden de alistamiento general del virrey Colomera que, en caso de invasión, los navarros defenderían el Reino, pero que no podían ser obligados, según lo marcaba el Fuero General, a combatir fuera de sus fronteras. Además, si bien los navarros movilizados deberían mantenerse a sus expensas los tres primeros días, a partir del cuarto deberían ser retribuídos por la Hacienda Real. De cualquier forma, la Diputación recordaba que ella debía ajustarse en su proceder a esas normas y que sólo las Cortes navarras podían introducir modificaciones en lo relativo a la contribución militar de los navarros, razón por lo cual el rey debía de convocarlas para ello ${ }^{24}$.

23. Joseba Miren Goñi Galarraga, «Imagen política del País Vasco en algunos documentos franceses de la Guerra de la Convención (1793-1795)», en Historia del Pais Vasco. Siglo XVIII, Bilbao, Universidad de Deusto, pp. 247-294.

24. Luis Eduardo Oslé Guerendiain, Navarra y sus Instituciones en la Guerra de la Convención (1793-1795), Madrid/Pamplona, Ministerio de Defensa/Universidad Pública de Navarra, 2004, pp. 220-221. 
De hecho, la demora de las autoridades navarras y de los municipios navarros en atender las continuas peticiones de los jefes militares españoles de cara a un incremento del número de voluntarios sólo se palió en los momentos en que las ofensivas francesas amenazaban más peligrosamente, e incluso entonces se constatan recriminaciones por parte de las primeras de incumplimiento del pago económico debido al voluntariado por los representantes reales y del trato sufrido por el mismo a manos del ejército. Además, llegado ya a un estadio del conflicto, la Diputación y las Cortes insistirán que los miles de navarros movilizados (de 17 000, por ejemplo, en mayo de 1794) constituían una aportación más que suficiente que debería ser reforzada por tropas venidas de otros puntos de España ${ }^{25}$. De todos modos, en relación con el grado de compromiso de los navarros con la contienda, se ha dicho que incluso «a la altura de agosto de 1794, cuando la guerra está en su momento más comprometido (...) lo que advertimos son deserciones generalizadas [por parte de los paisanos movilizados], jefes naturales responsables de las mismas, y un congreso del reino tolerante y hasta complaciente que no castigaba ${ }^{26}$.

Por otra parte, desde muy pronto los representantes reales se manifestaron ambiguamente acerca de la lealtad de los navarros. En un dictamen de 1794 elaborado por el virrey Conde de Colomera y por D. Manuel Fernando Ruiz del Burgo en relación con la oportunidad de convocatoria de los Tres Estados navarros, pedida por la Diputación en agosto de 1793 para que éstos se encargasen de decidir acerca de las contribuciones de soldados navarros ${ }^{27}$, aquéllos afirmaban que no cabía dudar de aquélla ni tampoco de ningún contagio revolucionario en cuanto pensaban que aunque los navarros eran «vecinos de la Francia, no hay reino ni provincia más distante de las influencias de la infección que con tanta obstinación han intentado propagar los rebeldes y malos vasallos de aquella desgraciada potencia. En los corazones de los navarros tienen la religión y la fidelidad al soberano un lugar de preferencia inaccesible a los embates de la sedición y la perfidia». Ahora bien, por otro lado, no dejaban de mencionar el temor «de que un espíritu faccioso, de imposible previsión en un congreso numeroso, produzca inquietudes y desavenencias de aquel reino». Esa segunda posibilidad empujaba a los firmantes «a creer será lo más acertado el que se suspenda la celebración de las Cortes».

\section{III.3 La Guerra de la Convención y Navarra. Deserciones en el frente y perturbaciones del orden público}

Las reticencias de los representantes del poder central podían estar justificadas, además de por los obstáculos interpuestos por las instituciones navarras a las

25.Ibid., passim.

26. Rodrigo Rodriguez Garraza, «Actitudes políticas en Navarra durante la guerra de la Convención (1793-1795)», Príncipe de Viana, 1990, 189, p. 116.

27. Ese dictamen puede verse en Fernando de Arvizu, «Las Cortes de Navarra en la Edad Moderna (Estudio desde la perspectiva de la Corona)», en Las Cortes de Castilla y León en la Edad Moderna, Valladolid, Cortes de Castilla y León, 1989, pp. 602-605. 
peticiones militares de suministrar voluntariado autóctono, la lentitud de la respuesta y las deserciones de los navarros en el frente, aspectos todos ellos ya comentados más arriba, por las perturbaciones del orden público que tuvieron lugar en el verano de 1794. En la sesión de 30 de julio de 1794 las Cortes acordaron que el Consejo y la Corte Real tomaran medidas "para el sosiego y quietud del público que quiera perturbarse con las voces que se esparcen por el pueblo [de Pamplona] de desmedida livertad ${ }^{28}$. En un oficio que el 31 de julio envió el Congreso al regente del Consejo aquél era más explícito, expresando el temor a un motín. En él se decía: «en esta Capital y otros pueblos del Reyno se esparcen voces sediciosas alusivas a apetecer la higualdad, y aún amenazar con Insultos, e, Incendios las casas de algunas Personas distinción y carácter explicándose en este punto con la más desmentida libertad, y debiendo fundadamente rezelarse que semejantes tumultuarias expresiones que comienzan por un reprensible inconsiderado desaogo del vulgo se fomenten con el disimulo y terminen en comución popular, para cortar de raíz las trájicas resultas que en las circunstancias críticas del día podía ocasionar el dejar correr impunemente unas voces tan disonantes como perniciosas contemplo preciso que V. S. con consulta de Consexo y Corte acuerde en su remedio las Providencias correctivas, y preserbativas ${ }^{29}$. El regente contestó el 1 de agosto que «había en la Sala tres causas Pendientes, las dos sobre Pasquines fijados en las ciudades de Tafalla y Sangüesa, sobre especies alusibas a lo mismo, y la otra de la villa de Marcilla sobre iguales expresiones, haviéndose procedido a su adveriguación ha resultado no descubrirse el Autor de la de Sangüesa, algunos Yndicios contra el que se alla capturado en la de Tafalla, y aunque se descubrieron los de Marcilla, apareció ser efecto de una Ynconsideración, y ligereza sin haber precedido sesiones juntas, ni conciliábulos, tenidos con deliberación, y esta última se alla ya juzgada». Asimismo, el regente comunicaba que el Real Consejo había acordado «que por la Sala de Señores Alcaldes de Corte con todo aquel sijilo y reserva a que obligan la delicadeza, y gravísima ymportancia del asunto se tomen las más serias y efectibas Providencias para la adberiguación de los Autores de semejantes especies sediciosas, y rumores, a fin de que se sofoquen en su origen, y eviten las perjudiciales consecuencias que con la tolerancia pudieran seguirse al estado, y quietud pública, usando de la prudencia y circunspección necesaria para que no se trasluzca, ni se de motivo a excitar la atención pública». También solicitaba a las Cortes navarras que proporcionaran detalles específicos sobre las noticias que tuvieran acerca de los hechos que denunciaban «individualizando el origen de estas conminaciones con la expresión de Personas, Ciudades, Villas y Lugares para aplicar a estos males, el remedio con más oportunidad, tino y acierto» ${ }^{30}$.

28. Actas de las Cortes de Navarra (1530-1829). Libro 13 (1794), Pamplona, Parlamento de Navarra, 1995, pp. 165-166.

29. AGN, Guerra, legajo 10, carpeta 44. Citado en parte en Rodrigo Rodriguez Garraza, «Actitudes políticas ... », p. 116.

30. Ibidem. 
Esos incidentes aparecen también citados en una carta del virrey Colomera a Godoy de 16 de junio de 1794 en la que se comenta: «devo hacer presente a V. E. que los procedimientos atropellados, y nada equitativos de dicho Congreso, para la saca de la gente que ha devido concurrir a la defensa de la Frontera han causado muchos disgustos en la mayor parte de los Pueblos, y en el de Arguedas, alboroto en quasi todos sus vecinos, con insulto a la justicia, y a otras personas distinguidas del Pueblo, de que se ba a hacer información judicial por la Sala de Corte para imponer a los culpados el justo castigo que merecen; y también el autor de unos Pasquines que se han hallado fijados en las Plazas de la Ciudad de Tafalla, que contienen expresiones alusivas a la igualdad, aunque explicadas con diferentes sentidos, sobre cuio asunto se ba a averiguar igualmente lo cierto ${ }^{31}$. Incidentes similares hubo en Pamplona un mes después: en la sesión de las Cortes navarras de 9 de agosto de 1794 se hizo constar «que se oían fuera algunas voces poco favorables a la quietud pública» ${ }^{32}$.

Para Colomera todos esos incidentes estarían, no obstante, inducidos por agentes secretos franceses. En la carta ya citada explicaba a Godoy: «Es de recelar, que savedores los enemigos de la celebración de Cortes de este Reyno, y de las desarregladas providencias de sus Tres Estados, que han dado ocasión al desabrimiento, y desconfianza de sus naturales, y habitantes, promueban por emisarios, y partidarios ocultos, que no faltan en el país, sus quejas, animándolos a conmociones populares, para que por este violento medio sean atendidos; y así, para precaver los males que amenazan, comprendo es indispensable el pronto remedio que llevo insinuado ${ }^{33}$.

\section{III.4 La Guerra de la Convención y Navarra. Negociaciones entre las Cortes de Navarra y la República francesa.}

Con todo, la inquietud de las autoridades del gobierno de Carlos IV tenía más razones de peso que los motivos recogidos hasta ahora. Y es que, a la altura de mayo y junio de 1794, meses antes por lo tanto del episodio de negociación de independencia de Guipúzcoa por parte de las Juntas Generales guipuzcoanas, la República francesa planteó a las Cortes de Navarra la realización de negociaciones separadas dentro de las cuales estaría incluída la posibilidad de integración en el estado francés. En carta del virrey Colomera a Godoy de 23 de junio de 1794 se afirmaba lo siguiente: «Me ha asegurado una persona de mi confianza que el Papel Periódico que se ymprime en Paris con el nombre de MONITOR, y que se dio al público con fecha de 27 del último [27 de mayo de 1794] propone la Combención a los Tres Estados del Reyno de Navarra se

31. AHN, Madrid, Estado, legajo 3952. Citado en Txomin Castillo, «Konbenioko gerla Nafarroan. Gipuzkoa nazionalismorantz zihoan bitartean», Príncipe de Viana, 1986, Anejo 5, p. 219.

32. Actas de las Cortes de Navarra (1530-1829). Libro 13 (1794), Pamplona, Parlamento de Navarra, 1995, p. 183.

33. AHN, Madrid, Estado, legajo 3952. Citado en Txomin Castillo, op. cit., p. 219. 
unan a la República Francesa, con lo que lograrán un gobierno suabe, todas las franquezas, y ventajas que puedan desear de la alianza, y auxilios de una poderosa Nación, como lo es la Francesa. No he podido verlo, ni saber si ha trascendido esta especie a algunos de los Vocales del Congreso, cuias no sean rectas y propias de un fiel Vasallo; pero prometo que si atreviera a hechar la proposición en él, sería despreciada y rechazada con vigor generalmente, como me han dicho, después lo fueron las otras de que dí cuenta a V. E. en mi carta reservada del $15 »^{34}$. Asimismo, entre los fondos de Estado del Archivo Histórico Nacional de Madrid hay una carta que parece ser también de Colomera en la que se dice: «Es mui cierto que por tres veces distintas, y por tres distintos vocales (ninguno eclesiástico) cada día de los tres uno solo, se pronunció la especie de que la Convención de París convidava al Reyno de Navarra a tratar con ella vajo la principal condición de que conservaría a los Navarros, todos sus derechos, exenciones, etc. Esto pudo ser una simple relación de lo contenido en varios papeles de los muchos sediciosos que se introducen en España. De cualquier modo la proposición fue desechada con el mayor desprecio todas tres veces, levantándose el Presidente eclesiástico ponderando el atrevimiento, y lo sedicioso, escandaloso, y sacrílego de la proposición, siguieron todos los vocales de todos los tres estados protestando su lealtad, y que estaban prontos a morir por la religión, y por su Rey. Los que propusieron la especie destestable, protestaron también, que nada hacían más que referir lo que havían leído, y oído, y que estavan así mismo prontos a sacrificarse por su Rey. Sin embargo parece no debe olvidarse semejante avilantez por más que se desprecie; y si precaver cualquier consequencia o repetición con el sigilo, y prudencia que pide la materia $\aleph^{35}$.

\section{III.5 El debate sobre la variación de la constitución del reino. Propuestas para un ejército navarro propio}

Hay que señalar que ya una semana antes las Cortes navarras habían debatido cuestiones relativas a la variación de la constitución navarra que irían en perjuicio de la monarquía y que finalmente también habían sido rechazadas, por lo que se aconsejaba el cierre de las sesiones del legislativo navarro. En una carta del conde de Colomera a Godoy de 15 de junio de 1794 aquél narraba: «que oy he savido por persona segura, y vajo la mayor reserva que algunos vocales de los Tres Estados de este Reyno, juntos en Cortes, han hecho, a los mismos, barias proposiciones escandalosas, y que se dirigen a variar la Constitución, perjuicio del poder ejecutivo, que reside en la autoridad Real, cuia idea sobstienen con mucho calor; y aunque hasta ahora no han sido admitidas, se puede temer hagan impresión en lo subcesivo». Por ello recomendaba «que conbiniendo al servicio de Dios, al de S. M. y al de este Reyno, por las críticas circunstancias

34. Ibid., p. 221.

35. AHN, Madrid, Estado, legajo 4826. Citado en Txomin Castillo, op. cit., p. 222. 
en que se halla prefige yo término a los Tres estados para que concluyan sus sesiones, relativas a los servicios, y de más que tengan que arreglar; presten el devido juramento de fidelidad a S. M. y al Príncipe Nro. Sr., y se cierre el Solio» ${ }^{36}$.

A pesar de que se podría pensar que esa discusión sobre la variación de la constitución de Navarra y el «perjuicio del poder ejecutivo, que reside en la autoridad Real» tendría que ver con las ofertas de negociación planteadas por la República francesa, solamente hemos encontrado algunos reflejos documentales, ligeramente posteriores además, referidos a otras dos cuestiones: la primera, la conformación de un poder ejecutivo dimanado de las Cortes y corporeizado en juntas permanentes; la segunda, la alteración de la constitución militar del reino de Navarra ligada a la configuración de un ejército navarro estable.

Acerca de la primera cuestión, en la sesión de 24 de junio, ante la posibilidad de que el virrey suspendiera las Cortes, al igual que sucedió en una situación análoga en 1684, mientras se permaneciese "en el actual inminente riesgo", el Congreso navarro comunicaba que «siendo absolutamente indispensable el que queden de los Tres Brazos algunos que representen al Reyno y atiendan a los asuntos que hay peligro en la tardanza, hemos conferido, a imitación de lo propio que se hizo dicho año de 1684 , todo nuestro poder y authoridad a dos señores del brazo eclesiástico, quatro del militar y otros quatro de el de las universidades, confiando en la actividad y vigilancia de ellos desempeñarán tan importante encargo con la última perfección» ${ }^{37}$. Con todo, las Cortes no se suspendieron, sino que siguieron reuniéndose y en las sesiones de 18, 19, 21, 22 y 28 de julio se debatió acerca «del poder egecutibo en los Tres Estados» ${ }^{38}$.

En relación con la segunda cuestión, su punto de arranque sería la decisión de las Cortes del 21 de junio de 1794, en una reunión en la que previamente a ella se juró "guardar un escrupuloso silencio» sobre cuanto se iba a tratar, de llamar al Apellido (o movilización general) conforme al Fuero para llamar a 20.000 hombres por cuanto el Reino, según el duque de Osuna, estaba «en sumo peligro» ${ }^{39}$, solicitud repetida el 22 de agosto ${ }^{40}$. Esa decisión habría empujado a diversos miembros del legislativo navarro a elaborar documentos acerca de la conveniencia de que Navarra contara con un cuerpo militar estable propio. De esta forma, el 2 de julio de 1794 se presentaban dos memoriales, uno del conde de Echauz y otro anónimo. Aunque no tiene fecha, en otro día posterior, se habría presentado otro memorial elaborado por el Marqués de San Adrián. Esos tres documentos, de cuya trascendencia no se ha hecho eco la historiografía ${ }^{41}$, son ciertamente interesante porque planteaban la conformación

36. AHN, Madrid, Estado, legajo 3952. Citado en Txomin Castillo, op. cit., p. 215.

37. Actas de las Cortes de Navarra (1530-1829). Libro 13 (1794), Pamplona, Parlamento de Navarra, 1995, p. 112.

38.Ibid., pp. 152-163.

39. Ibid., p. 107; Luis Eduardo Oslé Guerendiain, Navarra y sus Instituciones ..., pp. 294295.

40. Luis Eduardo Oslé Guerendiain, Navarra y sus Instituciones ..., p. 297.

41. De entre las investigaciones que analizan los hechos acaecidos en Navarra durante la 
de un cuerpo militar estable propio de Navarra, lo que, desde luego, no podía ser visto positivamente por Madrid. Esto suponía una clara ruptura con las pautas habitualmente mantenidas por el reino navarro en cuanto a su contribución en hombres para cuestiones militares. No hay que olvidar que, según los fueros y leyes de Navarra y tal y como había quedado confirmado en las Cortes de Tudela de 1747, los navarros, en conformidad con la costumbre, «no podían ser obligados a tomar las armas salvo en caso de que el enemigo penetrase en su tierra, o se hallare sitiando un castillo o villa del antiguo reino. Salvo en estos dos supuestos, que en realidad se reconducían al único de la invasión extranjera, nadie podía levantar gente de guerra en Navarra sin el consentimiento de los tres brazos o estados, reunidos en Cortes Generales $»^{42}$.

El memorial de Echauz comienza constatando la inexistencia de auténticos militares entre los voluntarios navarros movilizados y plantea un servicio estable de 6000 hombres, recurriéndose al apellido en caso de invasión. Para ello hacía falta «formar una constitución militar». Para contar con ese «servicio estable u ordinario de campaña» de 6000 hombres hacía falta formar un cuerpo de 18 000, que se dividirían en tres tercios de 6000 que se alternarían en el servicio estable cada uno durante dos meses. Los 18000 hombres estarían mandados por un Comandante General que estaría sujeto «únicamente al Reyno junto en Cortes o en Diputación». Los mandos se elegirían entre la nobleza ${ }^{43}$. Sabemos que ese memorial se leyó en la sesión de las Cortes de dos de julio, pero tras su lectura solamente se le agradeció a Echauz "por su celo» ${ }^{44}$.

El memorial del que desconocemos su autor se titula Papel anónimo presentado a las Cortes sobre la conveniencia que resultaría al Reino de perpetuar los batallones de voluntarios que se habian levantado para la guerra con Francia; proponia también los medios para ello ${ }^{45}$. Datado también el 2 de julio, las actas de las Cortes dicen que «aunque se conferenció sobre él, no se tomó resolución» ${ }^{46}$.

El documento empieza, como no podía ser otro modo, con un canto a la fidelidad de Navarra, afirmándose que el Reino de Navarra constituía «nobilísima parte de la católica corona, glorioso antemural de la Francia, y generoso centro de la lealtad Espańola», siendo testimonio de ello el que «a pesar de las críticas circunstancias en que se mira el estado político de la Europa", Carlos IV hubiese tenido «la bondad de concederle que se juntara en Cortes, cosa que solo pudiera ser asequible considerada en innata fidelidad».

Guerra de la Convención, ninguna se ha referido a estos tres documentos. Solamente Oslé Guerendiain (Navarra y sus Instituciones ..., p. 325) se ha referido al primero de ellos.

42. José María Vallejo García-Hevia, La monarquía y un ministro, Campomanes, Madrid, Centro de Estudios Políticos y Constitucionales, 1997, pp. 409-410.

43. AGN, Guerra, Legajo 10, Carpeta 19: Plan propuesto por el conde de Echauz a las Cortes para poner en la frontera contra Francia un cuerpo estable de 6.000 hombres navarros.

44. Actas de las Cortes de Navarra (1530-1829). Libro 13 (1794), Pamplona, Parlamento de Navarra, 1995, p. 128.

45. AGN, Reino, Guerra, Legajo 10, Carpeta 20.

46. Actas de las Cortes de Navarra (1530-1829). Libro 13 (1794), Pamplona, Parlamento de Navarra, 1995, p. 129. 
Los puntos de la propuesta hablaban de que los oficiales y soldados que entraran «a servir en este cuerpo» deberían ser navarros y de que «la constitución de este cuerpo será de tropa ligera». Aunque en principio sería «obligación del Reyno completar el cuerpo cuando S. M. lo necesite, por cuyo medio podrá excusarse de otros mayores gravámenes en orden a exacción de gente», no parecía «difícil que el cuerpo casi siempre se mantenga en su legítimo pie de fuerza» por medio de soluciones como la de obligar a servir en él durante cuatro años a delincuentes implicados en delito de bajo perfil. En tiempo de paz estos batallones no permanecerían fijos en Navarra, sino que podrían salir fuera para adquirir experiencia militar y para fomentar el ascenso en la carrera militar de sus integrantes. En caso de guerra con Francia, estas tropas no deberían salir de Navarra, pagándoles el reino un sobresueldo para así «sobrellevar mejor las fatigas de la guerra» y facilitar "los reemplazos de las bajas que tubieren». Por otra parte, el nombramiento de mandos sería a propuesta de las Cortes o de la Diputación, siempre entre navarros que tuvieran la graduación correspondiente "por cuyo medio se proporcionan a los Patricios otras salidas, pues por ningún pretexto vendrán estrangeros a mandar estos Batallones, lo que acaso sucedería faltando esta claúsula».

Más allá de esas claúsulas esenciales, también se planteaba el establecimiento de un colegio de cadetes en el que los que ingresaran tuvieran «igual gracia que los que se hallan en el Colegio de Nobles de la Corte, o el de la Artillería de Segovia». Del establecimiento de ese colegio resultarían «al Reyno imponderables ventajas, porque en primer lugar estos cuerpos tendrán unos excelentes oficiales, que serán apetecidos por todos los demás, y así los naturales lograrán un continuo manantial de salidas; los Padres cuyos hijos fueren colegiales no tendrán que sufrir los extraordinarios gastos que regularmente cuesta la carrera Militar».

No obstante, más allá de lo planteado hasta el momento, se sugería un segundo plan que se hacía «indispensable atendidas las actuales críticas circunstancias». Considerando "los perjuicios y gravámenes» suscitados al reino desde el inicio de la guerra, y que iban además en aumento, y considerando, asimismo, la necesidad de armonizar «tres especies que parecen incompatibles, y son la Guerra la Población, y Agricultura», se decía que "para llebar a efecto esta idea es preciso alterar la constitución del Reyno ${ }^{47}$ reduciéndola a la siguiente. Todo Navarro estará obligado a servir a la Patria desde la edad de 17 años hasta la de 56». Para compatibilizar la conformación de contingentes militares con los intereses demográficos y agrícolas, se pensaba en diversas medidas. Así por ejemplo, se dividiría a la población masculina en tres categorías: una primera clase de solteros desde los 17 años hasta los 56; una segunda, de casados desde los 17 años hasta los 45; y una tercera, desde los 45 a los 56 años. Los de la primera clase serían los primeramente movilizados, asumirían los destinos más alejados y harían instrucción militar en sus pueblos una hora todos los domingos, mientras las demás clases se ejercitarían con mayor intervalo

47. Subrayado nuestro. 
temporal. Asimismo, las familias aportarían soldados según el número de hijos que tuvieran y se tendrían en cuenta las circunstancias demográficas de cada hogar.

No nos podemos dejar de referir al hecho de que hacia el final del documento se habla de la necesidad de inculcación de valores navarristas puesto que se dice "para que nadie ignore desde su niñez las obligaciones que ha contrahído por nacer en Navarra, deverán imprimirse las que fuesen en preguntas, y respuestas, para que las aprendan de memoria, siguiendo un estracto de la Ystoria del Reyno (que puede hacerse a imitación de la de Espańa del padre Ysla) y las ordenanzas, ejercicio y pequeńa táctica que debe establecerse para lo que se lleva referido». Esto debería «enseñarse en las escuelas después de los compendios de Religión que regularmente se dan».

El tercer plan fue redactado por, nada más y menos, el Marqués de San Adrían, compañero de fatigas de Cortes en la Real Sociedad Tudelana de Deseosos del Bien Público. Carece de fecha y se habría debatido también entonces en cuanto que en las sesiones de 18, 24 y 28 de julio, se debatió «el plan presentado por la junta para el servicio momentáneo» o servicio estable militar ${ }^{48}$, por lo que aquél se habría presentado antes. El documento tiene como título Plan de una nueva constitución militar dirigido a las Cortes de Navarra por su vocal el marqués de San Adrián. Sigue un papel de reflexiones sobre los reparos que podian objetarse al plan; y una práctica para hacer efectivo el armamento general del Reino, según el plan de la nueva constitución militar ${ }^{49}$. Con todo, este documento carece de las aristas subversivas que podían advertirse en el anterior, anticipándose explícitamente San Adrián a limar cualquier posible apreciación de ese tenor.

San Adrián plantea, al hablar de las pautas tradicionales seguidas en Navarra en relación con la movilización de contingentes militares en caso de invasión, «las ruinosas consecuencias» de la práctica del Apellido o movilización general de la población masculina útil, por estar formado «tumulturiamente de una multitud guerrera, pero sin las Armas competentes, orden, ny prebia disciplina que necesita para nuestra común defensa». En su opinión, a finales del setecientos, momento «en que por un Sistema Político, abrazado por todas las Potencias cibilizadas del Globo, el cuerpo respetable de la tropa, bien armado, y disciplinado, es el que solo constituye la fuerza pública de los Reinos, y con ella la tranquilidad y sosiego de los mismos se hace preciso se hace preciso su permanente establecimiento en Navarra, si no queremos hacerla algún día la víctima miserable del bárbaro furor de los franceses». El recurso al apellido tenía como efecto el "desconcertar todo el orden y clases del Estado», al exigir a las personas abandonar sus actividades productivas. Además, «la nobleza puesta al frente de esta multitud indisciplinada y sin orden, ha de tener siempre un mando desairado y muy expuesto a sacrificar el honor de su concepto, y decoro de las irregularidades y capricho de un Pueblo y vulgo inculto a quien

48. Actas de las Cortes de Navarra (1530-1829). Libro 13 (1794), Pamplona, Parlamento de Navarra, 1995, pp. 152-163.

49. AGN, Reino, Guerra, Legajo 10, Carpeta 43. 
no le son familiares las Máximas del honor ny conocidas como debe las reglas de la subordinación, el orden y la disciplina». Por otra parte, el apellido conllevaba una irregular y deficiente disponibilidad de pertrechos y una falta evidente de conocimientos de táctica militar entre los soldados movilizados, lo que redundaba finalmente en la limitada operatividad de dicho sistema de movilización.

Los cálculos aplicados por San Adrián a la población navarra, ponderados por parámetros relativos al número de soldados similares a los empleados para la conformación del ejército prusiano, fijaban en 10.556 hombres los que constituirían "el cuerpo militar de Navarra», estructurados en once batallones y 91 compañías. Este nuevo sistema precisaría de un alistamiento general regular de todos los individuos de cada pueblo, introduciéndose algunos criterios de exención en el caso de imposibilitados, hijos únicos y de individuos que por su cualificación fueran «de absoluta necesidad al Pueblo». Como es de suponer según el origen social del proponente, los cargos de oficialía quedaban reservados para los nobles. El mando de los batallones sería fijado por las instituciones del reino entre «Personas entresacadas del exército" por méritos de graduación y de mérito militar, "prefiriendo para dichos empleos en igualdad de circunstancias a los que tubieren la calidad de naturales del Reino». Verificados los alistamientos, los soldados se seleccionarían mediante sorteos en cada pueblo. Habría dos batallones en cada merindad, a excepción de en la de Pamplona, donde habría tres, habiendo un cuartel en la capital de cada distrito. Los soldados se ejercitarían dos meses al año, en los meses de abril y mayo, pagándose «el prest correspondiente». Concluídos esos meses de entrenamiento, los soldados regresarían a sus pueblos. Cada dos años, en los mismos meses mencionados, se juntarían todos los batallones para ejercitarse en cuestiones de táctica militar de mayor enjundia. «Esta misma repetición de campamentos propagará insensiblemente por el País, un cierto entusiasmo y espíritu Militar que hará Marcial y Guerrero el carácter de todos los Navarros». Con todo, en el cuartel de cada merindad habría siempre cinco compañías permanentemente dispuestas.

Tras todo lo anterior, San Adrián se adentra en explicar las «ventajas que resultan de esta nueva constitución Militar». Además de poder disponer así Navarra de "un pie respetable de tropas» que, con la ayuda de las tropas nacionales españolas enviadas por el rey, garantizarían la defensa del territorio, la cualificación militar de los batallones navarros sería, asimismo, muy superior al de los contingentes movilizados mediante el apellido. También se evitarían las distorsiones que el sistema tradicional originaba en la agricultura, tal y como se estaba comprobando por aquel entonces. De cualquier forma, en caso de peligro extremo, se podría decretar excepcionalmente una movilización general similar a la tradicional, pero con la ventaja de que, tras la implantación del nuevo sistema, se contaría con veteranos adiestrados.

De forma llamativa, San Adrián, al final de la primera parte del documento, se hace eco de las posibles reservas a sus planteamientos, aunque limitándose 
a señalar las procedentes de las instituciones del reino, pero sin apreciar las que podrían provenir de Madrid. "Pero como puede haver algunos, que tal bez, equibocando los sobresaltos de una tímida cavilación con los nobles sentimientos del Patriotismo, les parezca que un establecimiento de esta naturaleza, bendrá a ser un cuerpo, numeroso de Milicias, que sugete al Reino a los servicios comunes de ellas, y que por más que se coarten sus funciones, y se restrinjan a la defensa del territorio propio de Navarra, las estenderá el Poder, y la Política del Gobierno a las demás Provincias y destinos forasteros con ruina en tal caso de nuestro País. Devo también satisfacer a esta objeción diciendo que si todas las constituciones y fueros de Navarra, no tienen otra barrera respetable que las defienda civilmente contra la fuerza del Poder sino sus leyes ¿por qué no podrá asegurarse con las mismas, la religiosa observancia de este nuevo establecimiento? Impóngasele pues silencio perpetuo a la boz de la desconfianza, para que no grite contra un pensamiento tan venéfico, fundado únicamente en la posibilidad y los temores de la transgresión criminal de una ley cuya violencia (incompatible con la benignidad y justicia que caracterizan a nuestro Augusto Soberano) solamente podrá destruir lo que sobre este particular se pacte». Para finalizar, en línea con las reflexiones anteriores, San Adrián, basándose en «el servicio sagrado de la Religión, el del Rey y el de la Patria», hace un llamamiento a las Cortes a apoyar esa propuesta de «nueva Constitución Militar» en cuanto que "concilia al parecer, los intereses de la Causa de Dios, los del César, y los vuestros» y en cuanto que «la nación enemiga que teneis al frente para destruiros, sus Máximas ympías, incompatibles con la pureza de la verdadera Religión que profesamos, y las que publican el fanatismo y el orgullo francés para la subversión de los Tronos, piden todos nuestros esfuerzos».

En la segunda parte del documento, titulada «Reflexiones y satisfacción sobre algunos reparos que pueden objetarse contra el Plan de la nueva Constitución Militar del Reino de Navarra", se repiten los argumentos ya expresados anteriormente, sin que se introduzca ninguna consideración novedosa.

Como veremos más adelante, en esos planteamientos de alteración de constitución militar del reino se advierte un halo de incertidumbre y de recelo ante el futuro del reino navarro por efecto del contexto bélico del momento, así como el convencimiento de la necesidad de que el mismo se defendiera militarmente por su cuenta, aspectos ambos que también se detectan en el documento redactado por Cristóbal Cortés a finales de junio de 1795, cuando las tropas convencionales francesas estaban a punto de entrar en Pamplona y de conquistar seguidamente el centro y el sur de Navarra.

Las peticiones de llamada al apellido de 21 de junio y de 22 de agosto, así como esas propuestas de alteración de la constitución militar del reino, no habrían sido del agrado del gobierno de Madrid. El 23 de agosto el virrey contestó a la segunda de las solicitudes de llamada al apellido afirmando que no le parecía oportuno porque «juntándolos tumultariamente, nos tiene acreditada la experiencia, con repetición, que sólo sirven para consumir dinero, armas y víveres y, destruir sus mismas poblaciones, faltándonos en lo crítico del lance 
y sin que pueda cortar estos abusos por traer el mal de su origen, con respeto a carecer de la imposición de las leyes penales militares, único freno que sujeta y contiene en sus deberes al soldado». En su lugar, recomendaba que se formaran batallones de voluntarios ${ }^{50}$. Una semana antes las tres personas comisionadas por las Cortes ante el gobierno de Madrid y ante el rey (el obispo de Pamplona, el marqués de Fontellas y Cristóbal María Cortes) se habían entrevistado con el monarca, a quien expresaron la preocupación de las instituciones navarras por la precaria defensa del reino de Navarra ante los franceses, afirmando Carlos IV que no dudaba de la fidelidad de dicho reino y prometiendo que haría todo lo necesario para asegurar su protección ${ }^{51}$. El mismo día de dicha entrevista los tres comisionados habían conferenciado con el Ministro de la Guerra, quien les detalló las medidas que se estaban tomando y los refuerzos que se iban a enviar. No obstante, los representantes navarros juzgaban que los apoyos de los que se les hablaba iban encaminados, no a auxiliar a Navarra, sino a articular una segunda línea defensiva mucho más al interior, en Vitoria, Burgos y Zaragoza. Asimismo, manifestaban que habían manifestado su recelo, "y quizás en términos demasiado fuertes, pareciéndonos un abandono, pero nos han cerrado la boca con decir que nuestro virrey tenía facultades ilimitadas y todo iba a su orden por lo que podría emplearlo donde más conviniese». Por último, en su correspondencia con las Cortes navarras se hacían eco de que el rey no sólo estaba «instruído (...) del estado actual de ese reino y necesidades de socorro, sino que también lo estaba de varias expresiones que se han vertido en el Congreso con alguna imprudencia, sobre lo que ha instado para saber si podría contar seguramente con la fidelidad de V. S.», aludiendo con ello a las informaciones publicadas en el Moniteur parisino. Los comisionados respondieron al monarca con «fuerza y vigor (...) asegurando que ese fidelísimo Reino derramaría la última gota de sangre, antes que apartarse del dominio de tan digno Dueño» ${ }^{52}$.

\section{III.6 El temor a la expansión de la ideología revolucionaria en 1795}

Hasta julio de 1795 apenas hay informaciones que debamos comentar. Solamente podemos mencionar algunos documentos que mencionan que en la zona ocupada por los franceses, éstos no fueron contemplados negativamente. Así por ejemplo, en la sesión de 24 de julio de 1795 de las Cortes de Navarra se alude a un papel de ratonera en el que se habla de la condescendencia de los franceses con los navarros en los pueblos que han ocupado, permitiéndoles que "continúen con sus usos y costumbres, pero sin obligación ni sujeción alguna de su parte (...) por cuios lisonjeros y engañosos medios consigue el hirlos seduciendo ${ }^{53}$. Esto se podría explicar por la circunstancia de que las consignas

50. Citado en Luis Eduardo Oslé Guerendiain, Navarra y sus Instituciones ..., p. 325.

51. Ibid., p. 332.

52. Ibid., pp. 332-334

53. Actas de las Cortes de Navarra (1530-1829). Libro 14 (1795), Pamplona, Parlamento de Navarra, 1995, pp. 313-314. 
difundidas por los comisionados políticos a las tropas revolucionarias hablaban de "proteger a la población pacífica, respetar los domicilios y las propiedades» $\mathrm{y}$ de que «los ricos únicamente sufran las contribuciones»" ${ }^{54}$. Estas informaciones eran corroboradas por personas que vivieron en ese periodo de ocupación en localidades del valle de Baztán y que testificaron en un proceso abierto en 1795 en el Tribunal Eclesiástico contra los curas de aquéllas por haber abandonado a sus feligreses 55 .

De hecho hay testimonios que apuntan al temor de políticos de peso en Pamplona a que la simpatía hacia la ideología revolucionaria pudiera ser compartida por sectores más o menos amplios de la población. En abril de 1795 el príncipe de Castelfranco escribía a las Cortes del Reino lo siguiente: «Teniendo noticias ciertas de que los Franceses han hecho conducir a las cinco villas de Bastan, una porción considerable de Fusiles, y deviendo recelarse sea con el obgeto de precisar a sus naturales y demás del Valle a armarse contra nosotros, espero del acreditado celo de V. Y. y de quanto se interesa en el servicio del Soverano y bien de la Patria, se servirá por medio de sus circulares dar a entender a las Justicias de los Pueblos del espresado valle, exorten y animen a todos sus vecinos para que degen sus hogares y acudan a la villa de Miranda en este Reyno donde se halla el Tercer Batallón de Voluntarios, compuesto de Bastaneses, asegurandoles en mi nombre que serán bien admitidos en él para armarlos y vestirlos como los demás, y que se les auxiliará con quanto necesitan para su mejor manutención y subsistencia ${ }^{56}$. En la Barranca el deslizamiento ideológico pudo haberse producido incluso a pesar de haber vivido experiencias negativas: un memorial conjunto de todo el valle de 8 de julio de 1795, en el que se esponían las vejaciones, robos, etc. a que les obligaron los franceses desde noviembre, finaliza diciendo que, a pesar de todo, «la juventud tomará el partido de la libertad ${ }^{57}$.

\section{III.7 La desconfianza del gobierno central hacia las autoridades navarras en julio de 1795}

El mes de julio de 1795, el último de la contienda, sería «el más crítico y confuso " ${ }^{58}$ y en el que las tensiones entre los representantes del gobierno central y las instituciones autóctonas volverían a reproducirse. No olvidemos que «desde Madrid se pensaba ya en el final de la resistencia vascongada. Vitoria se rendía sin condiciones al tiempo que capitulaban todos los pueblos de Vizcaya y Alava, secundando las instrucciones del Gobierno de Madrid, mientras que Pamplona se hallaba prácticamente cercada desde Irurzun y la Ulzama ${ }^{59}$.

54. Joseba Goñi Galarraga, op. cit., p. 46.

55. Citado en Luis Eduardo Oslé Guerendiain, Navarra y sus Instituciones ..., pp. 383-384.

56. AGN, Reino, Guerra, legajo 12, carpeta 24.

57. AGN, Reino, Guerra, legajo 12, carpeta 49.

58. Rodrigo Rodriguez Garraza, «Actitudes políticas ...», p. 116.

59. Ibidem. 
El gobierno de Carlos IV no se recató de expresar su desconfianza hacia las instituciones navarras. Durante todo aquel mes el virrey Castelfranco se esfuerza para que las Cortes se trasladaran a Olite, animando a la población a evacuar la ciudad, resistiéndose el Congreso navarro y también el ayuntamiento pamplonés a todo requerimiento. La primera notificación del virrey data de 4 de julio de $1795^{60}$. En un oficio posterior, del 15 de julio, Castelfranco se mostraba sospechoso de la fidelidad de los pamploneses ya que mencionaba en dicho documento la posibilidad de que, «sitiada Pamplona, no resistiera el tiempo que debe esperarse por haber en ella las gentes y efectos que, por su número, devilidad u otras circunstancias, puedan ser obstáculo a la buena defensa». Asimismo, el virrey decía que "la prebención impone siempre al enemigo, así como se aprobecha de los descuidos y confianzas temerarias. Estas son las precapciones juiciosas que se siguen en la guerra, y el que resiste su execución y práctica pasará por la nota de descuidado o de preparador de las glorias del enemigo» ${ }^{61}$. En su decisión de abandonar Pamplona, las Cortes hacen referencia a esas insinuaciones como «hideas de una sombra» y defienden la probada fidelidad demostrada por el reino ${ }^{62}$.

Sobre la connivencia de sectores de la ciudad de Pamplona, el representante del gobierno central Zamora comentaba, dos meses más tarde, en carta a Godoy de 18 de septiembre de 1795: «En esta ciudad (Pamplona) no había a mi juicio otro afecto al Rey que él». Y en otra carta anterior, de 10 de agosto, refiriéndose a todo el país vasconavarro, decía: "Yo en mi conciencia comprendo que la generalidad de la nobleza y gentes ricas de aquel país han abrazado de corazón a los franceses. Lea V. E. en apoyo de esto las copias de las cartas adjuntas que son las primeras gentes de Bilbao y Vitoria y de sus parientes y amigos». Este testimonio se veía avalado por el general Moncey, quien, a través de su confidente, comunicó a Zamora que «tenía grandes y seguras inteligencias en la Plaza de Pamplona», sobre todo entre "los eclesiásticos, los frailes, unos 20 nobles, los comerciantes y los curiales» de esta ciudad. El texto de Moncey se extiende en valoraciones similares para las otras provincias vascas ${ }^{63}$.

60. Actas de las Cortes de Navarra (1530-1829). Libro 14 (1795), Pamplona, Parlamento de Navarra, 1995, pp. 275-279.

61. Ibid., pp. 296-297.

62. Ibid., pp. 294-295.

63. Rodrigo Rodríguez Garraza, Tensiones de Navarra ..., pp. 220-221; Rodrigo Rodríguez Garraza, «Actitudes políticas ...», pp. 117-118. No obstante, tampoco los comentarios de las instituciones navarras en relación con Zamora eran precisamente elogiosos. En la sesión de 3 de julio de 1795 las Cortes de Navarra criticaron a Francisco Antonio de Zamora porque el día anterior «en la plaza pública del Castillo y a presencia de un concurso de personas bastante numeroso» había divulgado la cercanía de 31.000 soldados franceses tras presentarse «en dicha plaza en trage de camino y sin haberse suelto todabía las espuelas». Esas se difundieron por el pueblo "produciendo en la jente débil aquella conmoción unibersal que hera una consecuencia precisa del influxo y significado de ellas» (Actas de las Cortes de Navarra (1530-1829). Libro 14 (1795), Pamplona, Parlamento de Navarra, 1995, pp. 273-274). 


\section{III.8 La desconfianza de las autoridades navarras hacia la monarquía. Un papel anónimo de Cristóbal Cortés y Vitas.}

Sorprendentemente, el 24 de julio se leyó un papel anónimo de ratonera, preparado para la sesión de las Cortes de ese día, en el que su autor, que firma como Un navarro, pero que fue identificado por Yanguas y Miranda, catalogador de la documentación de la sección de reino del Archivo General de Navarra en los ańos treinta del siglo XIX, como el seudónimo utilizado por el diputado por Tudela Cristóbal María Cortés y Vitas, expone las eventualidades ante las que podía verse el reino de Navarra, con el ejército francés a las puertas de Pamplona ${ }^{64}$. En ese documento figuran diversas «apuntaciones sobre que puede caer la discusión en la sesión del 24 de julio», estructuradas en 26 párrafos.

Aunque ese documento se caracteriza por ser de una descodificación complicada, no cabe dudar de su trascendencia, así como tampoco del hecho objetivo de que todo apunta a que, en una coyuntura crítica como la de julio de 1795, Cristóbal Cortés se erigió en la persona que propuso a las instituciones navarras los caminos a seguir frente a las tropas francesas. Desde luego, esa actuación invita a presuponer que nuestro personaje alcanzó un peso político notorio, sobre todo porque aventurarse a hipotetizar sobre escenarios políticoinstitucionales a corto plazo y, más aún, plasmarlo en un documento, en aquel contexto de aguas turbias, debe ser interpretado como una empresa arriesgada y valiente. Más allá de ese documento específico, la consulta de las actas del legislativo navarro en las reuniones de los años 1794-1797 nos descubre a un Cortés, representante de la ciudad de Tudela ${ }^{65}$, ciertamente activo que aparece repetidamente como el representante del brazo de universidades. Su notoriedad se ve corroborada por varios hechos. El 30 de julio de 1794 las Cortes decidieron que, entre los que tenían que ir a a Madrid "en legacía», debía estar precisamente el literato tudelano, en representación del brazo de las universidades, y que con él marcharían el obispo de Pamplona y el marqués de Fontellas ${ }^{66}$. Su estancia en la capital, destinada a la negociación de las condiciones del servicio de voluntarios, fue de varios meses, ya que regresaron el 1 de octubre, y se saldó con el éxito ${ }^{67}$.

64. AGN, Reino, Guerra, Legajo 13, Carpeta 2: La portada, obra de Yanguas, reza: Papel anónimo de ratonera apuntando las especies que deberian tenerse presentes por las Cortes en la sesión de 24 de Julio. Son mui interesantes porque su autor (que aunque procuró desfigurar su letra se conoce ser don Cristóbal Maria Cortés diputado de Tudela) pone con mucha previsión y delicadeza todos los casos en que podía verse el Reino, ya defendiéndose contra el ejército francés, y ya abandonado y en la necesidad de mirar independientemente por su seguridad (1795).

65. Cristóbal Cortés y Vitas y Felipe González de Castejón fueron nombrados representantes de Tudela en las Cortes de 1794 (AGN, Reino, Cortes, Su celebración, Poderes Reales, Convocatorias y Poderes de los pueblos, Legajo 26, Carpeta 15).

66. Actas de las Cortes de Navarra (1530-1829). Libro 13 (1794). Pamplona, Parlamento de Navarra, 1995, p. 165.

67. Ibid., p. 254. 
A continuación, acometeremos nuestra interpretación del documento, contando con los antecedentes expresados hasta ahora en el presente apartado, teniendo en cuenta que el lenguaje empleado es bastante críptico. De cualquier forma, en nota reflejamos la única interpretación realizada hasta la fecha y que es obra de Rodríguez Garraza ${ }^{68}$.

El párrafo 1 de ese documento dice: «El ánimo e intención de los enemigos (obren solos, o de acuerdo con otros) se manifiesta en la proclama de Vitoria de 17 de julio». El párrafo 2, «Debe suponerse que exigirán de nosotros lo mismo, que exigen de los Alaveses». Y el párrafo 3, «Si esperamos a hazer quanto exijan después de dominados, serán forzosamente las condiciones las que quiera el que nos domine». Es decir, en esos párrafos se presupone que en caso de tomar Pamplona, los franceses (y, se puede presumir, sus colaboradores autóctonos),

68. En «Fueros, liberalismo y carlismo en la sociedad vasca (1770-1841)» (Congreso de Historia de Euskal Herria, San Sebastián, Txertoa, 1988, tomo IV, p. 309), Rodríguez Garraza dice : «Hay un papel anónimo de la ratonera de las Cortes, presumiblemente de Cristóbal María Cortés, diputado de Tudela, titulado "Apuntaciones sobre qué puede caer la discusión (del Congreso) en la sesión del 24 de julio". El texto rezuma navarrismo. Admite la existencia en Pamplona y en el Congreso de colaboradores de Francia, cuyas intenciones se han visto en la proclama de Vitoria del 17 de julio, suponiendo "que exigían de nosotros lo mismo que exigen a los alaveses, es decir, que si esperamos a ser conquistados, Francia nos impondrá sus condiciones. Ahora bien, tampoco Madrid tiene la menor intención de defender Pamplona, según se deduce por los oficios del virrey y de la Corte". Por consiguiente -dice-, "nuestra suerte depende de nosotros y del partido que tomemos". Ahora bien, la suerte de Navarra depende de la conservación de la plaza de Pamplona. Por eso, no existe otra alternativa que el "Apellido", imponiéndoselo al virrey. Será por pocos días, porque se está preparando la paz, pero de esta forma Navarra estará luchando para que no se la incluya por la fuerza en los vastos planes que desconocemos y que pueden afectar a la constitución de Navarra. ¿Temería la constitución de una república vasca bajo la protección de Francia?. Si el virrey se opone al reino, éste quedará obligado "a mirar independientemente por su seguridad", y Navarra, reconviniéndolo con el manifiesto de Alava (17 de julio), ha de decir a Francia "que apetecemos la neutralidad como libres, no como dominados; (y que) será exacta y con la más inviolable fidelidad" ». Por otra parte, en "Actitudes políticas en Navarra durante la guerra de la Convención (1793-1795)», 1990, 189, pp. 116177, el mismo autor hace una lectura bastante similar del documento: «Un papel anónimo de la ratonera de las Cortes, presumiblemente de Cristóbal María Cortés, diputado de Tudela, leído en la sesión del Congreso del 24 de julio, explica la situación. Admite la existencia en Pamplona y en el Congreso de colaboradores de Francia, cuyas intenciones se han visto en la proclama de Vitoria del 27 de julio [sic], suponiendo "que exigían de nosotros lo mismo que exigen a los alaveses, es decir, que si esperamos a ser conquistados, Francia nos impondrá sus condiciones. Ahora bien, tampoco Madrid tiene la menor intención de defender Pamplona, según se deduce por los oficios del virrey y de la Corte". No queda, pues, otra alternativa que el "Apellido" y su imposición al virrey. Será por pocos días, porque se está preparando la paz, pero de esta forma Navarra estará luchando para que no se la incluya por la fuerza en los ocultos planes que traman los Gobiernos de Francia y Espańa, y que pueden afectar a la constitución de Navarra. ¿ Temería la constitución de una república vasca bajo la protección de Francia?. Por eso, si el virrey se resiste al "Apellido", Navarra acudirá a Francia, pero sobre la base de "que apetecemos la neutralidad como libres, no como dominados; (y que) será exacta y con la más inviolable fidelidad". Ahora bien, antes de llegar a este extremo, "sería conveniente consultar a todas las capitales" (vascas), manifestándoles que el enemigo "a título de una falsa paz y de una moderación en el principio, se apodera de una en una de todas las poblaciones ..."”. Hemos de decir que en su obra, Luis Eduardo Oslé Guerendiain (Navarra y sus Instituciones ..., pp. 437-439) solamente reproduce el documento, no interpretándolo. 
impondrán a los navarros condiciones similares a las exigidas a los alaveses, condiciones que, según se desprende de lo que se dice más adelante, serían de paz a cambio de neutralidad.

Del párrafo 4 («Por los oficios del Virrey, y respuesta de la Corte se ven los pocos recursos, y la falta de ideas reducidas a retardar algunos días la entrega de esta Plaza; por consiguiente nuestra suerte depende de nosotros, y del partido que tomemos») se desprende la conciencia del firmante de la escasa ayuda que se puede recibir de las tropas espańolas, así como la inevitabilidad de que los navarros asuman que su futuro depende de ellos mismos y de las actitudes que muestren. Además, el párrafo 6 («Como la suerte del Reyno, según los oficios del Virrey, y nuestro conocimiento, está unido a la de plaza; el principal medio, sino el único, será la conservación de esta a cualquier costa») incide en la circunstancia de que la conquista de Pamplona abriría la puerta a la conquista de Navarra entera. En el párrafo 7 («Según los mismos oficios se debe suponer con bastante inmediación la pérdida de la plaza, y más si se advierte el curso regular de las cosas») vuelve a remarcar que la conquista de Pamplona se sustanciaría en cosa de días.

De todo lo anterior se infiere que "para no sufrir la ley del enemigo, se necesita recurrir a algún medio estraordinario» (párrafo 8). De entre esos medios extraordinarios, «el mas ovio es el de procurar repeler la fuerza con la fuerza levantando el apellido» (párrafo 9). El apellido o movilización general de la población navarra masculina útil se considera «el medio más seguro» $y$ "parece que debe pensarse en prepararle sin tardanza alguna» (Párrafo 11). La opción debería comunicarse al General en Jefe de los ejércitos espańoles (párrafo 12), venciendo «cualquiera oposición, que haya en el sistema adaptado por el General, pues seguido por el exercito bastaría a desvaratar la idea más enérgica» (párrafo 13) y no debiéndose "omitirse medio alguno, aunque sea valiéndose de quantos rodean al General» (párrafo 14).

De cualquier forma, también se maneja la hipótesis de que la Corte está negociando a la espalda de los navarros, estando el ejército español engañado por una hipotética negociación que se concretaría tras la conquista de Navarra y que formaría parte de un plan más global en el que estarían incluídos otros territorios, presumiblemente, a la luz de los planteamientos de Moncey de unos meses antes, los demás vascopeninsulares. Al menos, eso es lo que se deduce del párrafo 10 en el que se señala que otra opción alternativa a la del apellido «también lo fuera abrir los ojos a nuestro exercito tal vez engańado con la esperanza de una falsa paz, tal vez persuadido, que esta se dilata hasta la sujeción de éste Reyno, quando todo anuncia un proyecto más general».

La puesta en marcha del apellido deberá hacerse «en la firme persuasión, que nada tendrá fuerza, si no obran de acuerdo el Reyno, la capital, y los demás Pueblos, fiando absolutamente al primero la dirección» (párrafo 15). Con todo, incluso combinando el apellido con el ejército, el cual sería «el medio más enérgico", hay que ser consciente que no se podría «subsistir sino pocos días, durante los quales se ha de intentar llegar al fin que se proponga» (párrafo 16).

Planteado todo lo anterior, para Cortés se abrían dos escenarios. En caso de 
resistencia, los franceses ofrecerían "paz, y neutralidad al vencido» y en cuanto a las consecuencias de la negociación posterior «puede sospecharse las que serán, aunque ahora afecte moderación para el logro de sus ideas ulteriores» (párrafo 19). En el segundo escenario, los navarros optarían por no ofrecer resistencia: «Si la paz se ofreze a quien está en estado de defenderse, y por lograrla, escusa llegar a ello, las resultas serán que la neutralidad, que exige la proclama de Álava sea real, y no aparente, ni precaria» (párrafo 20). De esta forma, "las resultas serán, que no esté el Enemigo con la libertad de hazer extorsiones, quando se le antoje, y pueda esperar tranquilamente Navarra el fin de algún vasto proyecto, que se entrevé, y no se distingue» (párrafo 21).

En los párrafos finales, Cortés aborda, no obstante, la unilateralidad de las acciones a tomar por parte de Navarra en caso de que el virrey no apoyase la iniciativa navarra o estuviera engañado, tal y como podría pensarse. En el párrafo 22 llega a decir: «Si el General nuestro no abrazase nuestra intención y procede engańado, o sin libertad, como se sospecha que ha sucedido hasta ahora, debe ponerse el Reyno en estado de pensar». La dirección del pensamiento del reino debería enfocar hacia su propia seguridad: «Si, haviendo hecho quantos esfuerzos ha podido, sin que le quede el menor escrúpulo en esta parte, y ofreciéndose al más extraordinario, que no se le admite, llegó el caso de considerarse abandonado, o próximo a ello; y está necesitado el Reyno a mirar independientemente por su seguridad» (párrafo 23). Lo más aconsejable sería apostar por la neutralidad, de forma que en los párrafos 24 y 25 se dice «Si en este perentorio caso, y no en otro, será seguro o tal vez forzoso para defender la libertad Navarra, manifestar al enemigo nuestras ideas, reconviniéndole con el último manifiesto de Álava, en que exige la neutralidad, y diciéndole Que apetecemos la neutralidad como libres, no como dominados; pero que será exacta, y con las más inviolable fidelidad».

Con todo, antes de llegar a esa oferta de neutralidad fiel en estado de libertad, Cortés apunta en el último párrafo que «puede también pensarse (en caso de dar lugar) si sería conveniente consultar a todas las Capitales, exponiendo abiertamente y con toda precisión el estado de las cosas; y manifestando con la luz más clara, que el enemigo a título de una falsa paz, y de una moderación en el principio, se apodera de una en una de todas las poblaciones; subyuga por parte a la España, y va a dar la ley a toda ella; en cuyos términos es notable el letargo de no hazer causa común, para poner dique a tan ambiciosos, quanto hipócritas intentos». Desde nuestro punto de vista, aunque no está clara lo de la alusión a "todas las capitales», ese llamamiento se dirigiría a consultar con Madrid, y quizás con representantes de las provincias vascongadas, acerca de los planes de los franceses que buscarían a partir del proyecto esbozado por Moncey en marzo y con la decisión tomada por las Juntas Generales en mayo reseñados más arriba, si bien en aquél no se contemplaba a Navarra sino solo a Guipúzcoa, Álava y Vizcaya, tener una plataforma para anexionar más territorios españoles.

Las Cortes navarras asumirían ese análisis de Cortés y convocarían el apellido que el virrey Castelfranco hubo de aceptar. Firmada la paz de Basilea 
con Francia, de la que se informó a las Cortes de Navarra en la sesión de 5 de agosto de $1795^{69}$ y que no afectaba para nada al reino, 44 comisionados de las Cortes navarras reunirían para el 8 de agosto a 20.000 hombres de las diversas zonas navarras que no estaban ocupadas con sus armas. Las instrucciones, anacrónicas ya, que recibirían los comisionados para incentivar la movilización hablaban del trato sanguinario que habían sufrido las zonas ocupadas de la provincia y de los territorios adyacentes la ocupación de las provincias vascas y de la Navarra septentrional, advirtiendo que lo mismo sucedería con el resto de Navarra, «si ...no vuelan todos los naturales de la defensa de la religión, de su Rey y de su Patria». También se mencionaban como estímulos para la lucha la conservación de la propiedad y del orden establecido como estímulo fundamental por cuanto se mencionaba «qué monstruosa sería la alteración que palparíamos en el estado de las propiedades y personas?? ${ }^{70}$. El rey respondería positivamente a una representación de las Cortes navarras en la que se ponía en su conocimiento la decisión de llamar a todos los navarros para expulsar a los franceses ${ }^{71}$.

\section{El aumento de la presión del gobierno Central hacia NaVARRA}

Sea como sea, lo cierto es que la desconfianza del gobierno central hacia Navarra y los demás territorios vascopeninsulares se acrecentó tras la guerra de la Convención. Zamora animó a Godoy a combatir los fueros vasco navarros al comunicarle en carta de 10 de agosto de 1795 que «si a esta paz seguía la unión de las Provincias al resto de la Nación sin las trabas forales que las separan y hacen casi un miembro muerto del Reino, había V. E. hecho una de aquellas grandes obras que no hemos visto desde el Cardenal Cisneros o el grande Felipe V. Estas épocas son las que se deben aprovechar para aumentar los fondos y la fuerza de la monarquía». Y tras calcular que de las aduanas vasconavarras se podrían ingresar cuantiosos fondos y que se podrían extraer de las cuatro provincias 7000 hombres para el ejército, Zamora apuntaba que "hay fundamentos legales para esta operación: ellos han faltado esencialmente a sus deberes, cuesta su recobro a la Monarquía una parte de su territorio, y tenemos fuerzas suficientes sobre el terreno para que esto se verifique sin disparar un tiro, sin haber quien se atreva a repugnarlo [...]. Conozco que la obra en el día será odiosa a las Provincias; pero viendo que entrarán a disfrutar libremente las Américas, y a gozar de otros beneficios, sucedería lo que con Cataluña al principio del siglo, que lloró la pérdida de sus privilegios que desprecia hoy y ridiculizan sus propios escritores en el día». Asimismo, Zamora añadía en su carta que «Yo en mi conciencia comprendo que la generalidad de

69. Actas de las Cortes de Navarra (1530-1829). Libro 14 (1795), Pamplona, Parlamento de Navarra, 1995, p. 346.

70. AGN, Guerra, legajo 13, carpeta 6. Citado en Rodrigo Rodríguez Garraza, «Actitudes políticas ...», p. 117.

71. Luis Eduardo Oslé Guerendiain, Navarra y sus Instituciones ..., p. 442. 
la nobleza y gentes ricas de aquel país han abrazado de corazón a los franceses» y aportaba cartas sobre ello. Godoy respondió a esas propuestas llamando a no precipitarse diciendo «creo que quien tiene el derecho impondrá la ley, aunque se resistan a ella. Estas cosas son graves y, de momento, perderíamos más si nos diésemos por entendidos ${ }^{72}$. Con todo, el hecho de que Godoy estuviera en aquellos años dotado de un poder prácticamente absoluto, unido a la crisis hacendística, le animarían «a intervenir con energía para terminar con lo que consideraba trabas intolerables a la voluntad del rey por parte de las Provincias Vascongadas y de Navarra ${ }^{73}$. De esta forma, en septiembre de 1796 comienza una etapa en la que arrecian los ataques del gobierno central, acuciado por la crisis financiera, contra el autogobierno vascongado y navarro.

La ofensiva de Godoy empezaría con una Real Orden de 1 de septiembre de 1796 que sería revalidada en una Real Cédula de 17 de julio de 1799. En ella se ordenaba que se cerraran las Cortes navarras en el plazo de veinte días. Asimismo, se instauraba una junta de ministros para el examen del origen, causa y objeto de los fueros navarros que sirviera para el análisis de las bases legales de las representaciones enviadas por las Cortes y la Diputación en relación con las materias objeto de litigio (tabaco, vino, muselinas). También se mandaba que, mientras tanto, entrasen en vigor las disposiciones reales sobre aquellas materias, lo que equivalía a la suspensión del derecho de sobrecarta. En esa Real Orden se menciona taxativamente que la voluntad del rey debe ser la única referencia, situándose sobre cualquier otra ley. Se interpretaba que los fueros navarros eran privilegios concedidos por la soberanía del rey, que con arreglo a la voluntad regia eran susceptibles de modificación. En este sentido, Godoy afirmaría pocos meses después en relación con este asunto en contestación a las Cortes que «todas las cosas están expuestas a alteraciones según va igualmente la vida de las criaturas adormeciendo sus pasiones; no será extraño que aquellas primeras leyes [los fueros] se reasuman en la ejecución de las providencias [regias], al que, sin perder su fuerza, se las restrinja en el modo necesario según lo exijan las circunstancias ${ }^{74}$.

La respuesta de las Cortes navarras a esa Real Orden fue débil: fracasaron quienes propusieron retrasar la entrega del donativo y orquestar una protesta en regla "y se impusieron quienes opinaban que las circunstancias no permitían pruebas de fuerza y que era preferible esperar tiempos mejores». En carta a Godoy, las Cortes manifestaron que "por supuesto, no cabía admitir que una Junta de Ministros modificase las leyes de Navarra, cuando sólo las Cortes, junto con el rey, podían hacerlo» ${ }^{75}$. Hay que subrayar que en carta de Godoy a las Cortes navarras, en respuesta a la Representación de éstas y leída en la sesión de 4 de noviembre de 1796, se declaraba explícitamente que la decisión

72. Rodrigo Rodríguez Garraza, Tensiones de Navarra ..., pp. 227-228; Luis Eduardo Oslé Guerendiain, Navarra y sus Instituciones ..., p. 533.

73. Alfredo Floristán Imízcoz, La monarquía española y el gobierno del reino de Navarra, 15121808, Pamplona, Gobierno de Navarra, 1991, p. 279.

74. Ibid., p. 279.

75. Ibid., p. 280. 
de la administración borbónica venía dada porque «la enormidad de sucesos contrarios en la última guerra no han dejado expeditos los canales de la ejecución y se hace más indispensable el examen de los negocios» y el reino de Navarra «alteró sus principios quando la guerra, por haverse visto en necesidad de subrogar otros medios a los pactados en sus juramentos», no siendo "extraño que, por convenir al servicio del Rey, se haga también la novedad determinada por Su Magestad $»^{76}$. Las Cortes entendían que la variación de los principios durante la guerra tenía que ver con la convocatoria de una leva masiva mediante el apellido decretado, como vimos, a raíz del escrito de Cortés, pero razonaban que eso «fue con el único y preciso objeto de atender más ventajosamente al servicio de Vuestra Majestad», alegando la inconveniencia de las negativas del virrey a aquélla, por preferir «un número reducido pero organizado». De hecho, finalmente el reino obró «en esa subrogación de conformidad con el virrey, que investido de los reales poderes representaba inmediatamente la real persona de Vuestra Majestad», y, por tanto, «nada faltó en ese acto en lo que exige nuestra constitución para su legitimidad $»^{77}$.

La historia de esa Junta para el examen de los fueros fue muy accidentada y poco operativa. En realidad, ese órgano no se activó hasta que en 1800 la Cámara de Castilla insistió en su puesta en marcha con el fin de dar contestación a los memoriales de contrafuero que progresivamente iba presentando la Diputación contra las Reales Cédulas que, a partir de 1796, se consideraba que invadían las competencias forales. En la disposición que activaba tal órgano colegiado la Cámara de Castilla entendía que «los fueros estaban plagados de textos espurios o, cuando menos, dudosos; y que la interpretación que hacía el reino de muchos pasajes era infundada, si no maliciosa». De cualquier forma, a pesar de su constitución en 1801, tras unas pocas reuniones en las que no se sustanció apenas nada, no volvió a reunirse hasta 1806, limitándose «a solicitar del virrey que le enviase un ejemplar del Fuero General, de la Novísima Recopilación y de los cuadernos de Leyes de las Cortes que se habían reunido en el siglo", de lo que se desprende que la administración borbónica carecía de tal documentación en un ejercicio de total desidia e incuria ${ }^{78}$. Finalmente, una ley de las Cortes navarras de 1817-1818, en la que se consiguió la anulación efectiva de dicha real orden, afirmó que la misma en la práctica no había tenido ningún efecto ${ }^{79}$.

A partir de 1798, la urgente necesidad de captar más recursos financieros y militares, así como el ánimo de socavar lo más posible el régimen foral no sólo en contenidos, sino también en procedimiento, evitando el plácet de las Cortes, hizo habitual la imposición de la autoridad real mediante reales cédulas acerca de varias cuestiones (amortización de vales reales, reparto

76.Actas de las Cortes de Navarra (1530-1829). Libros 15 y 16 (1795-1801). Pamplona, Parlamento de Navarra, 1995, p. 329.

77. Ibid., p. 331.

78. Alfredo Floristán Imízcoz, La monarquía española ..., pp. 217-218.

79. Rodrigo Rodríguez Garraza, Tensiones de Navarra ..., pp. 230-234. 
de 300 millones de reales de vellón, etc.) que suponían la introducción de nuevos gravámenes fiscales en Navarra. En un documento conservado en el Archivo General de Navarra ${ }^{80}$ se compendian todos «los ataques con que se vió combatida la Constitución de Navarra desde el año de 1799 hasta el de 1801». A partir de 1800, la estrategia de la Diputación se dirigió a la consecución de una convocatoria de Cortes en dos representaciones de julio y de diciembre de aquel ańos, reconociendo en la última, «aunque sólo fuese con el objeto de ofrecerle servicios que llenasen sus soberanos designios, suspendiendo la ejecución de dichas Reales Cédulas». Esa estrategia la desarrolló por medio del concurso de un diputado enviado a Madrid como encargado de negocios (que sería precisamente Cristóbal Cortés) ${ }^{81}$ y de la intermediación, a partir de febrero de 1801, tras haber conocido «extrajudicialmente» el fracaso de una representación, de navarros con ascendiente en la Corte como José de Goya y Muniain, auditor de la Rota y próximo a Godoy.

Tras varios intentos frustrados, finalmente el 27 de marzo se informaba de que Goya había conseguido convencer a Godoy en una entrevista personal de que se pudieran reunir Cortes aunque fuera por breve tiempo y con el objeto único de tratar del donativo, extremos bajo los cuales la Diputación presentó una nueva representación. Finalmente, las Cortes se inauguraron el 20 de mayo, aunque con la amenaza de que, aún y todo, se llevarían a efecto las reales cédulas sobre contribuciones. Las Cortes se reunirán durante 20 días para el reparto que correspondía a Navarra de la contribución general de 300 millones, sin perjuicio de que permanecieran en vigor las otras disposiciones reales sobre contribuciones $^{82}$. Las Cortes ofrecieron al virrey un donativo de 15,5 millones de reales pagaderos en ocho años, mitad en numerario y mitad en vales reales, aunque en compensación de las cédulas de contribuciones. Ante la respuesta negativa del virrey, finalmente las Cortes, ante la dureza de la situación, delegarían en la Diputación la capacidad para aceptar el donativo, aunque éste fuera perjudicial en sus términos económicos, siempre y cuando se salvara «la sustancia de la Diputación del Reino». Hasta 1808 el gobierno actuó «en muchos momentos al dictado de Madrid cediendo en aspectos fundamentales

80. AGN, Reino, Legislación general y contrafueros, Legajo 22, Carpeta 4: Resumen o Cuadro histórico que presenta los ataques con que se vió combatida la Constitución de Navarra desde el año de 1799 hasta el de 1801 en que se consiguió la reunión de Cortes que se miraban ya como abolidas. Está reproducido en su totalidad en Rodrigo Rodríguez Garraza, Tensiones de Navarra ..., pp. 323326.

81. Aunque en su sesión de 3 de mayo de 1800 la Diputación había acordado que ese diputado tuviera el rango de encargado de negocios «con el único objeto de instruirse y observar reservadamente y con sigilo la disposición en que estaban los asuntos y el modo de pensar del Ministerio acerca de ellos», cuando el 16 de diciembre la sobrecarta del Consejo pone en ejecución las reales cédulas, la Diputación da plenos poderes al diputado presente en Madrid pues «conviene que todos sepan que la Diputación, haciendo cuantos esfuerzos le han sido posibles para conservar ilesa la legislación, no se contenta con sólo representaciones sino que tiene en la Corte uno de sus individuos para que aplique todo su celo en promover sus negocios» (Rodrigo Rodríguez Garraza, Tensiones de Navarra ..., pp. 257-258).

82. Rodrigo Rodríguez Garraza, Tensiones de Navarra ..., pp. 258-266. 
de su constitución» y diferenciándose el régimen de Navarra "cada vez menos del resto de la monarquía» a causa de la situación crítica del Erario público y los compromisos militares ${ }^{83}$.

\section{El papel jugado por Cristóbal Cortés entre i795 Y I80 I}

En la sesión de 3 de febrero de 1796 Cortés fue elegido como «vocal [de las Cortes] que ha de ir a la corte con el carácter de encargado de los negocios del Reyno». Como quiera que, excepcionalmente, la votación no fuera "por brazos», sino "en globo», es decir, con todos los representantes en conjunto, la circunstancia de que saliera elegido Cortés da idea de su carisma en todo el Congreso navarro ${ }^{84}$. Dos semanas después, el 17 de febrero de 1796 Cortés fue elegido como miembro por el brazo popular de la Diputación que había «de quedar representando al Reyno desde la conclusión de las Cortes hasta la apertura del solio de las primeras» ${ }^{85}$.

Los asuntos sobre los que debía negociar Cortés en Madrid se explicitaron en la sesión de 26 de febrero de 1796 en la que se leyó, además, una carta de aquel del día 23 en la que comunicaba que partía para la Corte. A Cortés se le encargaba el seguimiento de los diferentes asuntos pendientes entre Navarra y el gobierno central, entre ellos el relativo a las operaciones del apellido ${ }^{86}$. Si bien a lo largo de toda la estancia de Cortés en Madrid se leyeron en las Cortes cartas suyas informando de la marcha de los asuntos mencionados más arriba, en varias ocasiones el Congreso navarro deslizó sus sospechas de que la tardanza en la recepción de algunas sería debida a la interceptación de las mismas por parte del gobierno central. Así, en la sesión de 18 de abril de 1796 se dijo que Cortés no había escrito desde el 22 de marzo y se acordó escribirle "para que insinue el motivo de ese silencio» ${ }^{87}$. Por otra parte, en las sesiones de 10 y de 15 de junio de 1796 quedó reflejado que, ante la falta de misivas de Cortés, se le escribiera por si ese hecho podía ser ocasionado a «la interceptación de ellas, como antes se sospechó» ${ }^{88}$. El 15 del mismo mes se vuelve a repetir la misma sospecha .

La misión de legacía de Cortés se prolongó hasta el 9 de septiembre, fecha en la que, tras sopesar «las pocas esperanzas» que transmitía sobre los negocios del reino el mismo Cortés en una carta, el legislativo navarro se acordó que regresara ${ }^{89}$. Con todo, en la sesión de 4 de julio ya se había debatido sobre la continuación de la embajada, decidiéndose entonces que prosiguiera ${ }^{90}$.

83. Ibid., 273.

84. Actas de las Cortes de Navarra (1530-1829). Libros 15 y 16 (1795-1801). Pamplona, Parlamento de Navarra, 1995, p. 137.

85. Ibid., p. 146.

86. Ibid., pp. 152-153.

87. Ibid., p. 185.

88. Ibid., p. 230 y p. 234.

89. Ibid., p. 286.

90. Ibid., p. 244. 
Finalmente, el 11 de octubre Cortés «dio cuenta de su comisión» ante las Cortes $^{91}$.

Hay que decir que en las actas de la Diputación las ausencias de Cortés a las sesiones eran relativamente frecuentes, seguramente en razón de su residencia en Tudela. En la sesión de la Diputación de 13 de mayo de 1800 se leyó una carta de Cortés en la que éste comunicaba que "pasa a la Corte a acompañar a su hija que la llaman varios tíos, y que se detendrá en ella alguna temporada» ${ }^{92}$. El resto del año siguió en Madrid. Aprovechando esa circunstancia, en la sesión de la Diputación de 22 de diciembre de 1800 se le encomendaron funciones de representación a Cortés para tratar de las Reales Cédulas ${ }^{93}$. A lo largo de los meses siguientes se leyeron diversas cartas suyas sobre el seguimiento de la cuestión en diversas sesiones de la Diputación.

La estancia de Cortés en Madrid duró hasta abril de 1801. En la sesión de la Diputación del 24 de ese mes se leyó una carta suya escrita en la que manifestaba «haviendo ya salido la resolución de cortes [las de 1801], ha resuelto restituirse a este Reyno" ${ }^{94}$. En la sesión de 25 de abril de 1801 se acordó pagar a Cortés 6 duros por día por «toda la temporada que ha permanecido en Madrid» como representante del reino ${ }^{95}$.

Unos meses después finalizaba el recorrido de Cortés en la Diputación. El 10 de junio de 1801 se eligía por parte de las Cortes de Olite de 1801 la nueva Diputación ${ }^{96}$.

\section{Un manuscrito inédito de Cristóbal Cortés SOBRE LA CONSTITUCIÓN DE NAVARRA}

Todas esas informaciones sirven para dar razón del trasfondo de elaboración de un manuscrito redactado por Cortés hacia 1800 ó 1801 y titulado Constitución de Navarra. Ydea sucinta de la constitución de Navarra, hasta hora inédito, y que hemos hallado entre los fondos de la Biblioteca del Marqués de San Adrián en Tudela ${ }^{97}$.

91. Ibid., p. 312.

92. AGN, Libro de actas de la Diputación de 10 de julio de 1799 a 20 de mayo de 1801, f. 79 verso.

93. Ibid., f. 148 verso.

94. Ibid., f. 180 recto.

95. Ibid., ff. 181verso-181 recto.

96. Ibid., p. 414.

97. Archivo Municipal de Tudela, Constitución de Navarra Por Don Cristobal Cortes Natural de Tudela. Ydea sucinta de la constitución de Navarra [Manuscrito], Biblioteca del Marquesado de San Adrián, 30-B/3 (7). El manuscrito está encuadernado junto con otras obras. La fecha de 1800 que figura en el Catálogo Colectivo del Patrimonio Bibliográfico de Navarra es una «fecha probable de composición deducida de las obras con las que está encuadernada». Nosotros somos más bien de la opinión de que se datación correspondería a 1801, a la vuelta de Cortés de Madrid como representante de la Diputación en la Corte. 
En ese manuscrito, Cristóbal Cortés emplea el concepto de Constitución a la manera, tal y como era habitual en la época, del concepto de constitución entendido como Verfassung o constitución material o política propugnado por el historiador austríaco Otto Brünner en su obra Land und Herschaft de 1939, centrada en la organización sociopolítica de los territorios del archiducado de Austria hasta el siglo XVIII. Tomando los conceptos de Carl Schmitt, ese autor distinguió entre el texto legal supremo de los sistemas constitucionalistas de los estados liberales contemporáneos (llamado en alemán Konstitution) y la constitución material (o Verfassung) de los siglos medievales y modernos, previos por tanto al liberalismo, que servía para organizar la coexistencia de poderes en un determinado marco territorial, así como el reparto de funciones estatales (de confección de normas jurídicas, de administración de justicia, de gobierno, de recaudación fiscal, de reclutamiento militar, etc.) entre ellos, y que para su adecuada comprensión exige conocer cuál es la concepción del derecho existente en esa sociedad y que actúa como fundamento del orden jurídicopolítico vigente. $\mathrm{Y}$ es que en un contexto como el del estado moderno de los siglos XVI, XVII y XVIII, caracterizado por la convivencia entre un poder supremo y un conglomerado de poderes de niveles espacialmente intermedios e inferiores, tratando aquél, mediante el ejercicio jurisdiccional, de gobernar las complejas realidades territoriales, la Constitución correspondiente a ese tipo de Estado era una constitución política o estamental, cuya misión era la de conformar «un ordenamiento general capaz de organizar el proceso de gobierno y las relaciones entre los distintos poderes y sujetos agentes del territorio» ${ }^{98}$. Hay que recordar en ese sentido que ya Hotman en su Franco-Galia había definido constitución como conjunto de «instituciones y costumbres del reino, confirmadas en el curso de los tiempos» ${ }^{99}$. El empleo de tal término como sinónimo de la expresión leyes fundamentales, significando en su acepción más amplia la estructura jurídico-política del reino, se afianzará en el siglo XVIII, sobre todo gracias a Montesquieu quien restó valor a factores como la antigüedad, la existencia de un pacto originario o la voluntad del soberano para conferir trascendencia a las leyes fundamentales, al afirmar que cualquier tipo de gobierno (fuera democrático, aristocrático, monárquico, o despótico) tenía las suyas, debiéndose de regular con arreglo a ellas ${ }^{100}$.

De hecho, Joseph de Olmeda y León, autor en 1771 de Elementos del Derecho Público de la Paz y de la Guerra, siguiendo a Vattel, definió la Constitución del Estado como «el reglamento fundamental, que determina el modo como se debe ejercer la Autoridad Pública» y como "el establecimiento del orden, que una Nación se propone seguir en común, para conseguir las utilidades, en vistas de las que se ha establecido la Sociedad Civil», viéndose en ella «la

98. Maurizio Fioravanti,«Estado y Constitución», en Maurizio Fioravanti (dir.), El Estado moderno en Europa. Constituciones y derecho, Madrid, Trotta, 2004, pp. 18-30.

99. Maurizio Fioravanti, Constitución. De la antigüedad a nuestros días, Madrid, Trotta, 2001, pp. 58-63.

100. Javier Varela, Jovellanos, Madrid, Alianza, 1989, p. 69. 
forma, por la qual la Nación trata en qualidad de Cuerpo Político: cómo, y por quién, el Pueblo debe ser gobernado, y los derechos, y obligaciones de los que gobiernan ${ }^{101}$. Asimismo, con anterioridad a la aprobación de las primeras constituciones liberales, el término constitución era admitido en el Diccionario de la Real Academia Espańola con arreglo a aquella acepción. En la primera edición del mismo de 1729, figura la acepción de Constitución entendida como «Ordenanza, establecimiento, estatuto, reglas que se hacen y forman para el buen gobierno y dirección de alguna República o Comunidad». A partir de la edición de 1789, y a lo largo de todas las ediciones que se suceden desde entonces hasta mediados del siglo XIX (esto es, las de 1791, 1803, 1817, 1822, 1832, 1837 y 1843) a aquella acepción se añadirá otra, que incluso tendrá carácter preeminente sobre la anterior: la que interpreta dicha voz simplemente como «la forma, o sistema de gobierno que tiene adoptado cada Estado». Por lo tanto, durante la primera mitad del ochocientos, el significado académico del vocablo constitución no recogerá ninguna de las connotaciones que le confería el sistema liberal, gobernante en España en los lapsos de 1812-1814 y 1820-1823 y ya sin interrupciones desde 1837 (es decir, el de texto normativo supremo que no puede ser contradicho por ninguna otra regla de rango inferior), limitándose a indicar desde una perspectiva empírico-descriptiva el ordenamiento institucional existente de hecho.

Centrándonos en el análisis del manuscrito, en el inicio del mismo Cristóbal Cortés sigue la senda trazada por el discurso historiográfico de los cronistas navarros y por el discurso políticoinstitucional mantenido por las instrituciones navarras a lo largo de la Edad moderna. Antes de la elección del primer rey navarro se realizaron los pactos que fueron jurados por aquél y por todos los demás reyes hasta la fecha en que el autor del texto escribía. "Ocupada Espańa por los Moros, y reducidos los vascones al pequeño recinto que les ofrecia la aspereza de sus montes, pensaron en unir sus fuerzas para defenderse del ímpetu agareno. Juntáronse para elegir Rey, y antes de verificarlo hicieron varios pactos, que admitió y juró el primer Rey, y han jurado sin interrupción todos quantos se han seguido por espacio de 11 siglos hasta el Señor Don Carlos IV que felizmente reyna». Esos pactos jurados por los reyes son los fueros fundamentales, la constitución contractual en que se basó la monarquía navarra y por la que se sostiene la relación entre rey y reino: «Estos pactos admitidos, en virtud de los quales Navarra jura, y ha jurado sus Reyes y Señores, son los que llaman fueros fundamentales, tan antiguos como el Reyno; tan inviolables como él; y la sólida vase sobre que se erigió, y se conserva la Monarquía. No son ni pueden calificarse de meras exenciones, de franquezas, o privilegios; sino de constitución contraactual [sic], en que se funda la Corona».

El pacto se mantuvo con posterioridad a 1512, recordando Cortés la promesa de respeto a los fueros de Fernando el Católico. Asimismo Cortés recuerda el carácter de eqüeprincipalidad de la unión entre Navarra y Castilla: «Así era

101. Joseph de Olmeda y León, Elementos del Derecho Público de la Paz y de la Guerra, Madrid, 1771, 2 volúmenes, p. 32. 
forzoso que fuese; puesto que la unión fue eque principal y no subjectiva; y conservó cada uno de los Reynos sus fueros, prerrogativas y exenciones del mismo modo, que si estubieran divididos». Como consecuencia de esa forma de unión, ni los tribunales ni las leyes castellanas tienen valor directo en Navarra: «De aquí es que ni el Supremo Consejo de Castilla, ni la Real Cámara, ni otro tribunal alguno puede exercer en Navarra jurisdicción, por sí, o por delegación a Juez, o Ministro alguno; y por consequencia del mismo principio prohiven las Leyes que se den comisiones particulares con poder de decidir, o en otra forma».

Tras recordar que la obediencia de los navarros al rey y al virrey está supeditada al cumplimiento del juramento, Cortés recuerda el funcionamiento del mecanismo del reparo de agravios como garantía del mantenimiento del autogobierno navarro: «Siempre que se ha expedido cédula, que pudiese ofender estos primitivos pactos, que se llaman fueros, los tres Estados si están juntos en cortes generales, y en su defecto la Diputación representan a Su Majestad el agravio; y los Señores Reyes lo han reparado, y desecho el contrafuero aún después de sentencias pasadas en autoridad de cosa juzgada». "La práctica es tan constante y uniforme, que tiene en su apoyo la observancia de todos los Siglos. Todos los Monarcas, así antes como después de la incorporación de Navarra a la Corona de Castilla han conservado ilesos, y declarado inviolables estos primitivos fueros; $y$ han reparado qualquiera agravio, que ha podido causar aún la más urgente providencia».

A continuación Cortés se centra en explicitar cuáles son los fueros «que se consideran como fundamentales y primitivos», circunscribiéndose «a solas dos proposiciones, en que están eminentemente contenidas las principales livertades del Reyno de Navarra».

La primera ley fundamental de Navarra es «que el Rey (salva su Real clemencia) no pueda establecer leyes, disposiciones generales a manera de Ley, ni ordenanzas decisivas, que no sea a pedimento de los tres Estados, y con voluntad, consentimiento y otorgamiento de ellos». Para corroborarlo, cita el Capítulo $1^{\circ}$ Libro $1^{\circ}$ del fuero general, interpretando que los ricos hombres mencionados allí "son hoy los tres Estados del Reyno». En refuerzo de esa lectura, evoca a Moret, al mismo prólogo del Fuero General y a Pérez Valiente, autor éste del Aparato al Derecho Público Hispánico, obra publicada por primera y única vez en 1751. También alude a la práctica habitual de que «siempre se han establecido las Leyes con el consentimiento de los tres Estados», tanto en la Navarra independiente como en la de después de 1512.

La segunda ley fundamental es «la livertad, que tienen los Navarros de todo lo que sea constitución, o impuesto; y que los Reyes (salva su Real clemencia) no tengan derecho a su imposición antes de la concesión de los tres Estados. El mismo capítulo del fuero lo asegura por ser hecho mui granado: las Leyes 5, 6 y 7 del Libro $1^{\circ}$ título 25 lo confirman; y la observancia, que es el más fiel intérprete, que reconoce el derecho quando es uniforme, es un apoyo incontestable de esta verdad». Asimismo, menciona en relación ello diversas declaraciones de reyes navarros del siglo XV y en relación con el periodo 
posterior a 1512 se menciona a la declaración de contrafuero de la introducción de las alcabalas ensayada en 1517 , así como a la circunstancia de que «en todas las leyes contra-actuales de servicios hechos en cortes generales con inclusion de las últimamente celebradas en 1794 se halla constantemente la claúsula de ser gracioso y voluntario el servicio; y las reservas y condiciones, que contienen acreditan incontestablemente ser gratuito; pues en lo que es de necesidad no se pacta, ni estipula».

El resto del manuscrito insiste en «la extrema fidelidad de Navarra» y en el «esfuerzo generoso, que ha monstrado en otras ocasiones cumpliendo por su parte los pactos que juró; sin ceder jamás a Provincia alguna en el amor, y servicio de su soberano, ni en la disposición pronta y animada de ocurrir según sus fueros a las necesidades del estado». Teniendo en cuenta eso, Cortés aclara que las reivindicaciones navarras se fijan solamente en que la forma de aportar se corresponda con lo que dictan las leyes navarras, «que no se altere su amada, eterna e inalterable constitución», "que los servicios que preste sigan el inviolable método de los primitivos fueros, que pactó el primer Rey, y han jurado solemnemente todos sus subcesores por espacio de tantos siglos». En su opinión, estimando en 50.000 las familias existentes en Navarra, "comparado este pequeño número con la extensión de las demás provincias no será abenturado asegurar, que a pesar de sus libertades ha contribuído y contribuye en los servicios ordinarios y extrahordinarios, tanto como qualquiera de ellos proporcionalmente». Por último, pide que se sopesen las contribuciones realizadas por Navarra en los cuatro años anteriores, tanto en hombres como en dinero, aportando algunas cifras.

El abrupto final del documento parte del convencimiento de «que este reyno ha contribuído, y contribuye proporcionalmente tanto como qualquiera de las Provincias de España». La frase final del mismo ("Y en este estado de fidelidad y exfuerzo [sic] generoso puede ocurrir el pensamiento de alterar los sagrados derechos de una constitución jurada por 47 Reyes, y sostenida por los Navarros en 11 siglos a costa de su sangre y sus propiedades? ... La pluma se cae de la mano») encuentra su razón de ser en las experiencias negociadoras del propio Cortés y en su percepción de que los ataques al autogobierno navarro desde diferentes planos (el historiográfico, el político-institucional, el económico, etc.) podían conllevar a corto plazo el fin del mismo.

\section{A MODO DE CONCLUSIÓN}

En el presente artículo hemos analizado la faceta política e institucional de un dramaturgo neoclásico, el navarro Cristóbal Cortés. En sus obras, al igual que todos los demás autores de dicho género de esa época, perseguía, recurriendo a personajes históricos de la Edad Media o de la conquista de América, inculcar valores morales, sobre todo entre la alta nobleza y en los gobernantes, relacionados con la primacía de los intereses comunes sobre los intereses propios, con la moderación de las pasiones y con la idea de buen gobierno, objetivos todos 
ellos vinculados en cierta manera con la socialización del programa reformista borbónico en el que las metas a alcanzar era el reforzamiento de la autoridad del monarca y del Estado, la consecución del bienestar y la cohesión entre los elementos integrantes del conjunto de la monarquía.

Los sucesos sucedidos durante la Guerra de la Convención, así como las propuestas debatidas, en relación con Navarra no son fáciles de interpretar, sobre todo cuando las suspicacias mutuas expresadas por las autoridades reales y por las instituciones autóctonas las enmarañan notablemente. A falta de datos nuevos, e independientemente de que hubiera en Navarra un sector de opinión favorable a los franceses, la realidad es que las Cortes navarras desecharon la opción de negociar separadamente con la República francesa, que los comisionados de Navarra en Madrid (entre ellos Cortés) trataron de disipar las desconfianzas de la Corte y que lo único que objetivamente pudo erosionar la confianza en la fidelidad del aparato institucional navarro fueron las propuestas de conformación de un cuerpo militar propio de Navarra.

Bajo todo ello, la práctica política del dramaturgo tudelano, durante aquella contienda y en la ofensiva centralista de después, con su convencida defensa del sistema institucional navarro, podría parecer que le colocaría en un ámbito ideológico bien diferente al que se reflejaba en el trasfondo ideológico de los dramas neoclásicos de base historicista: el de los protectores de un particularismo territorial, todavía pertrechado de sólidas bases, pero que la administración central empezaba a socavar. No obstante, no hay que ver en esa dualidad ninguna disfuncionalidad. Dentro de la concepción austracista en la que se inscribiría Cortés, que contemplaba la monarquía hispánica como una nación de naciones, era perfectamente compatible la doble adscripción en el que el sentimiento de pertenencia a la nación más cercana era tanto o más significativa que el de pertenencia a la nación-monarquía ${ }^{102}$.

Por otra parte, también es posible pensar en las consecuencias de la valoración positiva de la Edad Media, realizada no sólo por la tragedia neoclásica histórica espańola de la época, sino también desde muchas otras esferas de la vida intelectual española en las que se constata «la identificación del contexto medieval como el adecuado para contextualizar y rastrear lo que tendía a identificarse como origen de la monarquía española, si se planteaba en clave política, o bien, como origen de la nación española, desde otras perspectivas más amplias» y también como justificación del modelo de centralización borbónica ${ }^{103}$. En el caso de Cristóbal Cortés la exaltación de las realidades políticoinstitucionales más próximas y del afán de sostenerlas con una mirada apologética hacia el pasado puede ponerse en relación con la tendencia a la ambientación medieval de los dramaturgos neoclásicos españoles de la que él participaba, algo que no afectó,

102. Javier Fernández Sebastián, «España, monarquía y nación. Cuatro concepciones de la comunidad política española entre el Antiguo Régimen y la Revolución liberal», Studia HistoricaHistoria Contemporánea, XII, 1994, pp. 47-49.

103. José Manuel Nieto Soria, Medievo constitucional. Historia y mito político en los orígenes de la España contemporánea (ca. 1750-1814), Madrid, Akal, 2007, pp. 29-30. 
como decimos, solamente a los autores teatrales ni mucho menos. De hecho, el aprovechamiento político de lo medieval en los debates preconstitucionales del periodo 1808-1812, presentando la monarquía visigótica altomedieval y los sistemas constitucionales forales como modelos de monarquías templadas que había que imitar en un ejercicio de impostura histórica protagonizado por todos los sectores políticos representados en Cádiz, fue la culminación de un proceso que arrancó varias décadas antes, constituyendo un ingrediente fundamental «en el transcurso de la evolución del pensamiento ilustrado espańol y de sus procesos de mitificación histórica» ${ }^{104}$. Seguramente el propio Cristóbal Cortés habría asistido estupefacto a la lectura, por parte de Agustín Argüelles el 18 de agosto de 1811, del Discurso preliminar leido en las Cortes [de Cádiz] al presentar la Comisión de Constitución el Proyecto de ella en el que se hacían destacadas referencias apologéticas a la constitución histórica de Navarra $^{105}$. En ese discurso se afirma como primera alabanza en relación con la Constitución histórica de Navarra que ofrecía «un testimonio irrefragable contra los que se obstinen en creer extraño lo que se observa hoy en una de las más felices y envidiables provincias del reyno; provincia en donde quando el resto de la Nación no ofrecía más que un teatro uniforme en que se cumplía sin contradicción la voluntad del Gobierno, hallaba éste un mural inexpugnable en que iban a estrellarse sus órdenes y providencias, siempre que eran contra la ley o pro comunal del reyno». El resto del párrafo será una continua loa de las instituciones tradicionales navarras ${ }^{106}$ que poco tendrá que envidiar a lo

104.Ibid., p. 10 .

105. Se puede consultar en Constitución politica de la Monarquía Española, promulgada en Cádiz a 19 de marzo de 1812, Reimpresa en la Imprenta Nacional de Madrid, Ańo de 1820, pp. 1-120.

106. «En el día todavía el reyno junta Cortes, que habiendo sido antes como en Aragón anuales, se han reducido a una vez cada tres años, quedando en el intermedio una diputación. Las Cortes tienen aún grande autoridad. Ninguna ley puede establecerse sin que ellas lo consientan libremente, para lo qual deliberan sin la asistencia del Virey; y si convienen en el proyecto, que en Navarra se llama pedimento de ley, el Rey le aprueba o le desecha. Aun en el primer caso las Cortes todavía examinan de nuevo la ley en su forma original ya sancionada; la resisten si la hallan contraria o perjudicial al objeto de su proposición, haciendo réplicas sobre ellas hasta convenirse el Rey con el reyno. Mas éste al cabo puede absolutamente resistir su promulgación e inserción en los quadernos de sus leyes, si no la juzga conforme a sus intereses. En las contribuciones observan igual escrupulosidad. La ley del servicio ha de pasar por los mismos trámites que las demás para ser aprobada, y ningún impuesto para todo el reyno tiene fuerza en Navarra hasta haberse obtenido otorgamiento de las Cortes, que para conservar mas cabal y absoluta su autoridad en esta parte, llaman a toda contribución donativo voluntario. Las cédulas, pragmáticas, \&c. no pueden ponerse en execución hasta haber obtenido de las Cortes o de la diputación, si están separadas, el permiso o sobrecarta; para lo qual se sigue un expediente de trámites bien conocidos. La diputación exerce también una autoridad muy extensa. Su principal objeto es velar que se guarde la constitución y se observen las leyes: oponerse al cumplimiento de todas las cédulas y órdenes reales que ofenden a aquéllas; pedir contrafuero en todas las providencias del Gobierno, que sean contrarias a los derechos y libertades de Navarra; y entender en todo lo perteneciente a lo económico y político de lo interior del reyno. La autoridad judicial es también en Navarra muy independiente del poder del Gobierno. En el Consejo de Navarra se finalizan todas las causas, así civiles como criminales, entre qualesquiera personas, por privilegiadas que sean, sin que vayan a 
sostenido por Cortés en su manuscrito de 1800-1801, basándose Argüelles en las informaciones suministradas por el diputado gallego Benito Ramón de Hermida ${ }^{107}$ en su opúsculo Breve noticia de las Cortes, Gobierno, o llámese Constitución del Reyno de Navarra, publicado en Cádiz en 1811, informaciones éstas fundamentadas a su vez en un informe elaborado por un exsíndico del Reino de Navarra en su estancia en Sevilla en 1809 para la Junta Central, en el momento de la Consulta al país, en el que se exponía, según afirmaba el autor en carta a Jovellanos, "con simplicidad la Constitución del Reyno» ${ }^{108}$.

los tribunales supremos de la corte los pleytos ni en apelación, ni aun por el recurso de injusticia notoria. Las provincias vascongadas gozan igualmente de infinitos fueros y libertades, que por tan conocidos no es necesario hacer de ellos mención especial».

107. Hermida nació en 1736 en Santiago de Compostela. Su padre era oidor de la Audiencia de La Coruña. Estudió derecho en su ciudad natal. De juez criminal de la Chancillería de Granada en 1768 y oidor en la misma chancillería en 1774, pasó a Regente de la Audiencia de Sevilla en 1786 y a fiscal de Cámara del Consejo de Castilla en 1792. Castigado por Godoy, se jubiló del cargo en 1802 y se expatrió en Zaragoza. Amigo personal de Jovellanos, fue nombrado Secretario del Despacho de Gracia y justicia por la Junta Central en octubre de 1808. La Regencia le nombró Consejero de Estado en febrero de 1810. Diputado en Cádiz por su provincia de nacimiento, participó activamente en los trabajos de la asamblea gaditana hasta el 25 de julio de 1811, día en el que tuvo un ataque de perlesía en el pleno, llegando a recibir el viático al día siguiente. A partir de esa fecha sus aportaciones pasaron a ser por escrito a causa de sus problemas de salud, siendo frecuentemente ignoradas. Finalmente falleció en Madrid en febrero de 1814. Desde el punto de vista ideológico, en los debates mostró un evidente conservadurismo. Cf. Jean-Baptiste Busaall, «Constitución histórica y revolución liberal: el reino de Navarra, ¿̨un modelo posible para la reforma institucional en las Cortes de Cádiz?», en Jean Baptiste Busaall y Lartaun de Egibar Urrutia, Las instituciones del Reino de Navarra en el debate histórico jurídico de la revolución liberal, Pamplona, Universidad Pública de Navarra, 2005, pp. 97-100; Joaquín Lorenzo Villanueva, Mi viaje a las Cortes. Obra inédita, Madrid, Imprenta Nacional, 1860, pp. 263 y 362.

108. Jean Baptiste Busaall, op. cit., p. 80. 